$$
\begin{gathered}
\text { UNIVERSITY OF CALIFORNIA } \\
\text { COLLEGE OF AGRICULTURE } \\
\text { AGRICULTURAL EXPERIMENT STATION } \\
\text { BERKELEY, CALIFORNIA }
\end{gathered}
$$

\title{
PRUNING BEARING DECIDUOUS FRUIT TREES
}

\author{
BY \\ WARREN P. TUFTS
}

\section{BULLETIN No. 386}

APrIL, 1925 



\title{
PRUNING BEARING DECIDUOUS FRUIT TREES
}

\author{
BY WARREN P. TUFTS
}

Pruning consists of cutting, removing or repressing certain living parts of the tree in order to modify and utilize its natural habits for the purposes of the grower. By pruning, the form of the tree is modified, its bearing regulated and thereby more and better fruit is obtained at less cost and for a longer period than is possible without pruning. The response of a tree to any kind of pruning is such, however, that it is practically impossible to modify its form without at the same time profoundly influencing its functions. There must be understood the various operations of pruning and how to apply these operations to obtain the responses which are necessary.

Briefly stated, the chief purposes of pruning are:

1. To produce a vigorous, mechanically strong, healthy tree.

2. To secure a tree well shaped for convenience and economy in orchard management.

3. To distribute the fruiting area well over the tree.

4. To secure fruit of good size and quality.

5. To regulate the annual succession of crops in order to obtain the maximum average crop compatible with good fruit.

The principles and practices of pruning young deciduous fruit trees have been discussed in a previous publication. ${ }^{1}$ The present discussion will be limited largely to a consideration of the pruning of bearing trees.

\section{TERMS USED}

Leaf-bud.-A leaf-bud contains the rudiments of a leafy shoot or spur.

Fruit-bud.-A fruit-bud contains the rudiments or unexpanded parts of a flower or flowers, with or without the rudiments of a leafy shoot.

Adventitious buds.-All buds arising in unusual or abnormal places, whether on parts below or above ground, are called "adventitious buds." The usual position for all buds, of course, is in the leaf axils (angles formed by leaf stalks and one-year wood) or at the tip of the shoots.

1 Tufts, W. P. Pruning young deciduous fruit trees. California Exp. Sta. Bull. 313: 111-154, figs. 1-24. 1919. 
Suckers and Water-Sprouts.-All growth arising from adventitious buds on the parts below ground are called "suckers," that arising from such buds on above ground parts and from dormant axillary buds "water-sprouts."

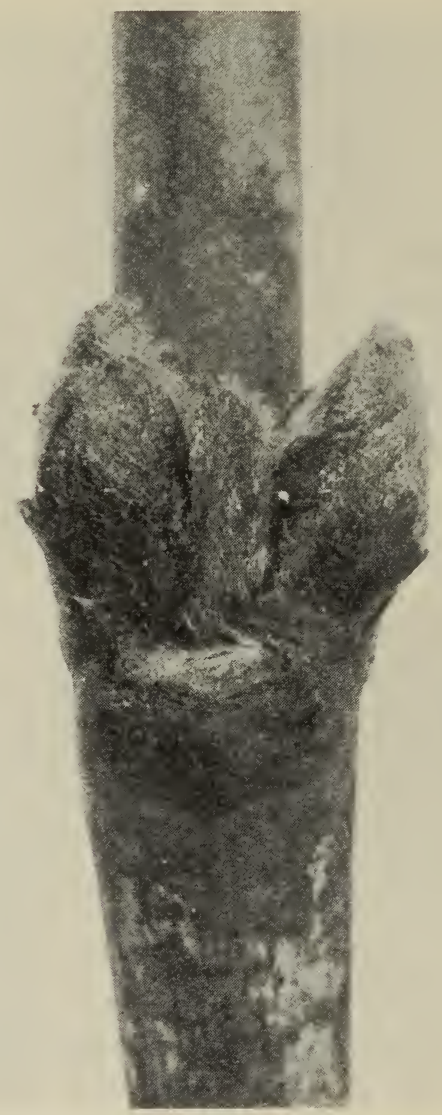

Fig. 1.-Fruit-bud of the peach. Note the two lateral fruit-buds with a small leaf-bud between.

Spurs.-Many species of fruit trees produce short shoots which bear flowers and fruit, and are called "spurs."

Current and One-Year Growth.-Any new shoot is referred to during the growing season as "current" or "this year's" growth. This same shoot, however, during the following dormant and growing seasons, is referred to as "one-year" wood. In the same way, reference is made to "two-year-old" wood, etc. 


\section{FRUIT BEARING HABITS}

In order to prune fruit trees intelligently, it is necessary to have a thorough understanding of the various kinds of buds and of their relation to the fruit bearing habits in the different species and varieties. The following classification is based on the location and external appearance of leaf- and fruit-buds.

Classification of Buds.-As to development, the kinds of buds are:

1. Wood- or leaf-buds, which develop into leafy shoots.

2. Fruit-buds, which are of two kinds:

(a) Flower-buds, which develop into a single flower (peaches, apricots, almonds) or several flowers (cherries, plums).

(b) Mixed buds, which develop into a cluster of leaves and flowers (apples, pears).

As to position, the kind of buds are:

1. Lateral buds, which are in the axils of leaves on the sides of the shoots.

2. Terminal buds, which are on the ends of shoots.

3. Adventitious buds, which are produced at unusual points (not leaf axils), on the roots, trunk, or branches.

Recognition of Fruit-Buds:

The positions of fruit-buds are:

1. On comparatively long shootș of the past season one-year wood.

(a) Lateral (fig. 1). In this position are found almost all the fruit-buds of the grape, peach, quince, and olive, many of the fruit-buds of currants and gooseberries, part of those of apricots, almonds, plums, cherries, and sometimes pears, apples, and walnuts; and the fruit-buds for the first crop of figs. Apricots, peaches, and Japanese plums often bear three buds at a node, in which case the center one is usually a leaf-bud, and the two outer ones fruit-buds.

(b) Terminal. This is the normal position of most of the fruitbuds of the walnut. Some varieties of apples and pears also frequently bear a considerable number of fruit-buds in this way.

2. On comparatively short shoots (spurs) of the past season. (These short shoots constitute either an extension of the spur system already established or the beginning of a new spur.) 


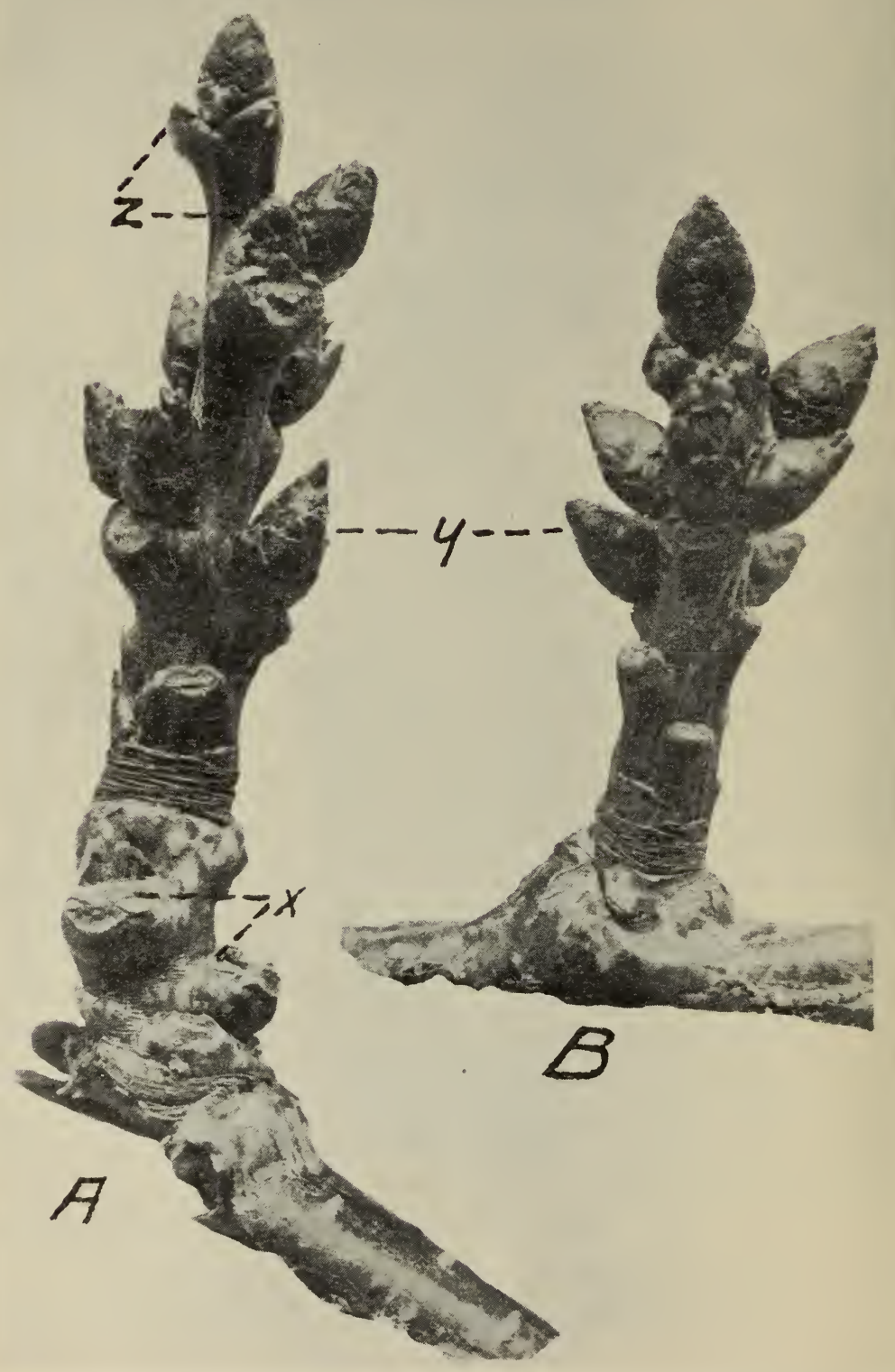

Fig. 2.-Apricot fruit-spurs. Scars where fruit has been produced at $X$. Fruit-buds at Y. Leaf-buds at Z. Two-year-old spur at A. One-year-old spur at B. 


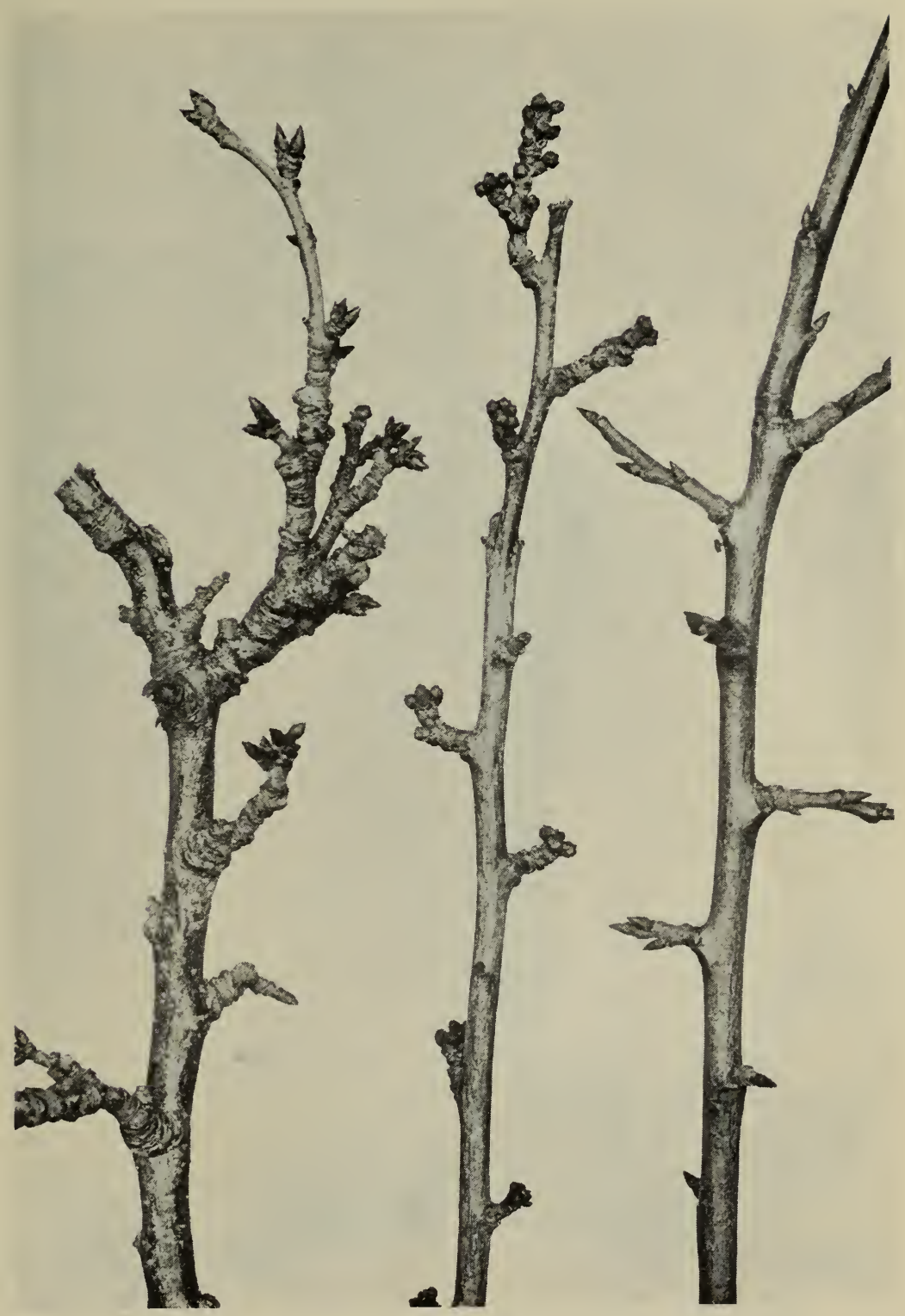

Fig. 3.-Fruit-spurs of plums. Left to right: Robe de Sargent (European); Wickson (Japanese); Yellow Egg (European). Note small roundish fruit-buds of the Wickson which are characteristic of Japanese plums. The Robe de Sargent has a more compact spur system than most European plums. 
(a) On-short-lived spurs, which may live only 3 years or less (fig. 2).

(1) Lateral buds. Most of the fruit-buds of apricots and almonds are in this position. Peaches occasionally bear a small part of their fruit-buds in this manner. All the fruit-buds of currants and gooseberries on shoots older than one year are borne in this way.

(b) On medium-lived spurs which may live 5 to 8 years (fig. 3 ). Plums bear most of their fruit-buds laterally in this way.

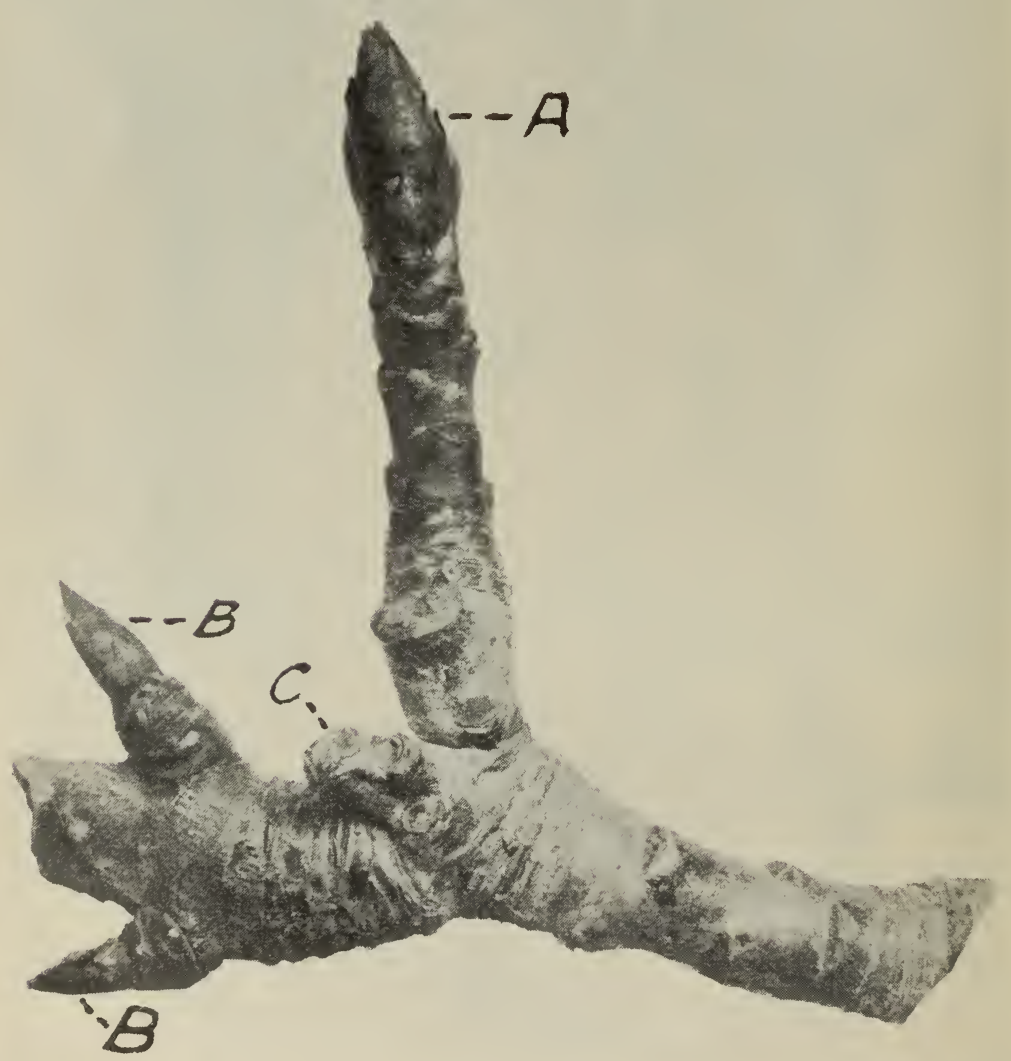

Fig. 4.-Three-year-old portion of a pear spur. Note terminal fruit-bud at $A$, and two lateral leaf-buds at B. Fruit was produced at C during season preceding that in which buds A and B were formed. Growth of "B'" buds will give rise to characteristic branching of older pear spurs. 
(c) On long-lived spurs which live 10 to 20 years, but which should be renewed (or at least invigorated) oftener.

(1) Lateral buds. Most fruit-buds of sweet cherries and part of those of sour cherries are borne in this way.

(2) Terminal buds (fig. 4). Most of the fruit-buds of the apple and pear are terminal.

The Appearance of Fruit-Buds.

The fruit-buds of the apple, pear, peach, apricot, and plum are larger and plumper and are not so sharply pointed as the wood-buds. Cherry fruit-buds are difficult to distinguish until they begin to swell. The most certain way of determining fruit-buds is by sectioning the bud lengthwise with a sharp knife or razor. The fruit-buds of the apple, pear, cherry, and plum contain several roundish bodies, each of which develops into a flower. The fruit-buds of the almond, peach, and apricot each contains the rudiments of a single flower. A pocket magnifying glass is of considerable help in this examination.

The following chart presents the above facts in a somewhat more concise manner:

\section{Positions of Fruit-Buds of Deciduous Fruits}
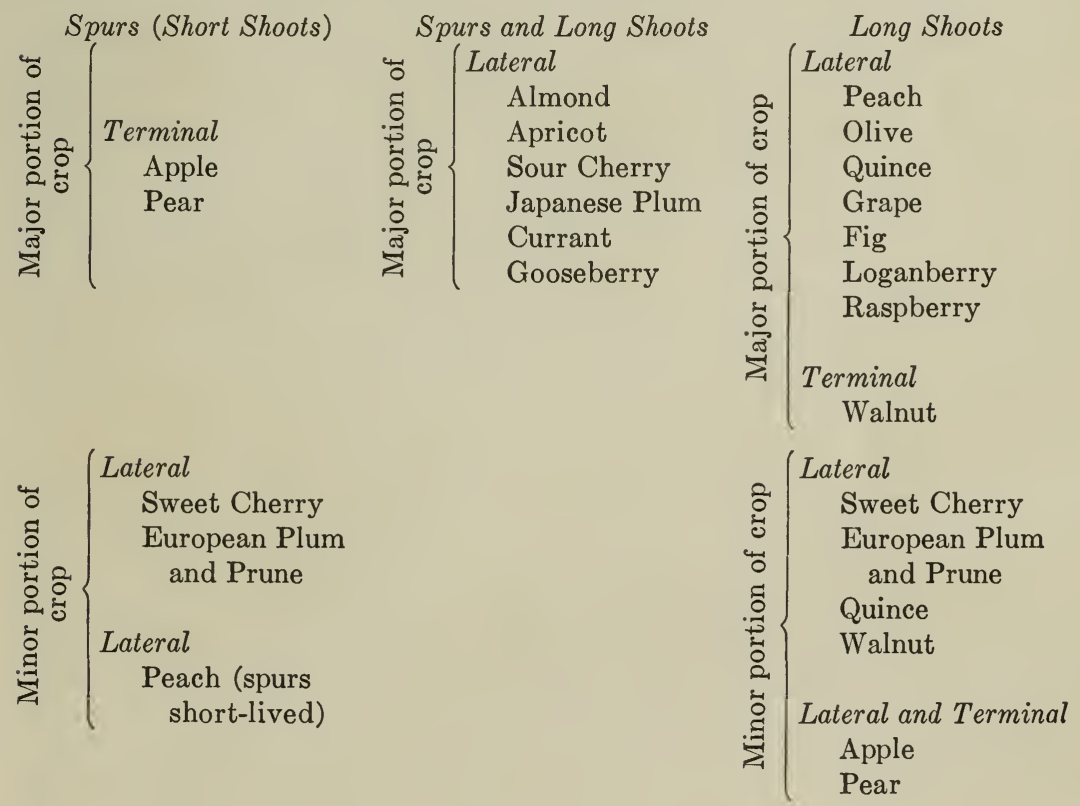


\section{THE SOURCE OF MATERIALS FOR TREE AND CROP}

In order to comprehend the responses of the plant to pruning, certain facts should be known concerning the annual cycle of growth and development of the tree. The first growth of the season (blossoms, leaves, and new shoots) is made largely at the expense of plant food reserves normally stored in the tree during the preceding summer and fall. These stored foods are thus at least partially used up during the early part of the summer. The soil solution containing mineral nutrients taken up by the roots is transported to the leaves where, with other substances built from the carbon dioxide of the air, the complex plant foods are elaborated. These foods are then carried to other parts of the tree for use or storage. After the active vegetative period of early summer is past, the plant begins to store such elaborated foods as are not used in the maturing of the current fruit crop, development of leaves, the extension of the top and roots, and the development of fruit-buds for the succeeding year's crop. Under favorable conditions, the storage of reserves for the winter months and for the growth of the following year becomes greater and greater as the season advances, at least until near the time of leaf fall.

A fruit tree with the crops it produces represent an accumulation of materials drawn from the soil by the roots and from the air by the leaves. When the materials from either source can no longer be obtained, it ceases to exist as a living thing. Since this is so, any plan of developing and managing an orchard from the time it is planted to the time it is no longer profitable, must take into consideration the treatment of the soil, and the treatment of the top, especially pruning. Trees develop or produce very differently in different locations, and respond rather readily to cultural practices. This being true, it is necessary to know what influence a change in the quantities and kinds of material available in the soil may have on the appearance and behavior of the top, especially in relation to materials already in the top, or to those being brought in by the leaves. Or from the other point of view-just what influence pruning, spraying, insect infestation, or any other factor may exert in changing the material income of the top, and its relation to the materials derived from the soil, and the subsequent development of the top? Only by such a consideration of orchird problems can they finally be worked out with certainty. The full so rion of this problem will require time and labor, but some progress has buen made, and it seems possible to give the orchardist a working insight into the problem at the present time, and to offer suggestions, as to the character of pruning and of the supplementary 
soil treatments that should be applied under varying conditions of growth and bearing. There is much observational evidence and no small amount of direct experimentation to show that plants respond very differently in growth and fruit production, according to the amounts of nitrogen available, the amounts of carbohydrates that can be manufactured, and the manner in which these are combined within the plant. Very great differences likewise may be brought about by variations in temperature and the length of the light period to which plants are exposed. Plants growing out-of-doors, supplied with sufficient moisture and subjected to the usual range of conditions will vary in development and productivity according to the amounts of nitrogenous materials available in the soil and to the amounts of available carbohydrates manufactured by the leaves or stored in the plants.

It is possible to distinguish four general classes or states of vegetativeness and fruitfulness of the plant in this respect.

1. Mineral nutrients including nitrates abundant but no available carbohydrate supply. Result: vegetativeness weak and plants nonfruitful.

2. Mineral nutrients including nitrates abundant and a carbohydrate supply available. Result: vegetativeness strong but little or no fruit.

3. Mineral nutrients including nitrates relatively less than in class 2. This reduces regetativeness and leads to an accumulation of carbohydrates. Result: fruitfulness.

4. Mineral nutrients including nitrates even relatively less than in class 3. Result: this leads to a marked accumulation of carbohydrates and a suppression of both vegetativeness and fruitfulness. ${ }^{2}$

Naturally these classes grade into one another, but it is possible to place trees in one or another of them with a considerable degree of accuracy, by observing the appearance and performance of the trees and knowing the general cultural conditions which have been employed. For the fruit grower, it is obviously impracticable to attempt an actual analysis of the trees in an orchard to dete:mine their chemical content and therefore the treatment as to pruning, irrigation, fertilization, and other cultural practices, which should be given. But, as indicated above, the crops produced and the new wood growth made, generally furnish an excellent basis for judgment and a fairly accurate decision as to what is happening in the plant. The author has attempted to cite below some points to be kept in mind in connection with the foregoing suggestions and instances in which fruit trees apparently fall in one or another of the above outlined classes.

2 Kraus and Kraybill. Vegetation and reproduction with special reference to the tomato. Ore. Exp. Sta. Bull. 149: 1-90, figs. 1-22. 1918. 
It has been demonstrated many times that heavy cutting, whether done on young trees or old, generally results in rank vegetative growth, and, if the trees are of bearing age, in reduction of fruitfulness. However, if in addition to the pruning, the trees are heavily fertilized and irrigated, the new growth will be still ranker and more succulent, and little or no fruit will be produced. On the other hand, no pruning, insufficient soil moisture and few available mineral nutrients will result in scanty new wood growth and, in bearing trees, a tendency towards over-production. If this latter treatment is continued trees soon reach a condition where there is neither wood nor fruit produced. Between these extremes may be found all gradations of vegetativeness and reproductiveness, depending upon the environment under which the plants are growing.

Fruit growers will readily call to mind orchards exhibiting varying degrees of vegetative vigor and fruitfulness. Unfortunately, many attempts in the past have been made to influence the wood growth and the productiveness of the tree by pruning alone. This is a mistake, since pruning is only one of the factors which modify plant growth and productiveness.

Cultivation, irrigation, and application of fertilizers are some of the other factors which must be considered along with pruning in attempting to regulate the vegetative growth and fruitfulness of an orchard.

Trees just planted have relatively little carbohydrate, but enough to start them into growth. As they develop, leaves are formed which manufacture a new supply of carbohydrates; and as the leaf area becomes greater this supply is increased, the roots are extended further into the soil, and the tree becomes vigorously vegetative, that is, it belongs to class 2 .

If, however, such young trees, or even older ones, are severely summer pruned so that the leaf area is seriously reduced, the food stored in the branches will be consequently removed, and the tree as a whole will fail to make as much growth as one less severely pruned, other conditions being the same. This would represent a class 1 condition.

On the other hand, if the young vigorous trees are not so severely cut back, the consequent larger leaf area will permit of a greater manufacture of carbohydrates, and provided the nitrogen supply is not markedly increased, there will be a tendency toward a decrease of vegetative activities, an increase in carbohydrate accumulation and the trees will become fruitful. Such plants are in class 3 . It is the ultimate aim of every commercial orchardist, to maintain his trees in 
this class and his main efforts in the way of cultivation, irrigation, pruning, and other cultural practices should be performed with the idea of securing a proper balance between vegetative growth and fruitfulness. The production of a large number of fruits is not profitable, unless it can be continued and for this a constant supply of new growth must be maintained as well. By knowing some of the materials concerned in the maintenance of this condition, and some of the means for their regulation, the fruit grower has a direct and fairly accurate method for securing the type of tree he desires.

The conditions of class 4 are commonly observed in old prune and pear orchards in California, which make little or no new growth and, although there is present a great number of fruit-spurs, little or no fruit is produced. In these cases the difficulty is frequently one of lack of nitrogen, because there is an accumulation of large quantities of carbohydrates stored in the top. Such trees as these when nitrogen and moisture are supplied, or if there is available nitrogen already in the soil, when moisture alone is applied, frequently are unusually productive for a year or two. Likewise, a pruning which removes much of the old wood and permits a relatively greater nitrogen supply to the branches and buds remaining results in a greatly increased vegetativeness of the remaining portions, often accompanied by abundant fruit production as well. But to attempt to regulate such trees by pruning alone would be futile, because to balance the top with the available nitrogen or moisture, would mean reducing the top to a size where it could hardly produce a commercial crop. It would be far more profitable to give the proper attention to soil requirements, as well as to a more rational pruning method.

\section{CORRELATION BETWEEN PRUNING AND OTHER CULTURAL}

\section{PRACTICES}

The above considerations emphasize the fact that pruning alone cannot be relied upon to regulate the growth and productivity of the orchard. It is doubtless one of the most important factors in determining the balance between carbohydrate and nitrogen supply, but a thorough understanding of the principles involved must be obtained before a rational pruning system can be adopted for any particular set of conditions.

There may be an adequate supply of available nitrogen, but if soil moisture is reduced to such an extent that the tree cannot utilize this food material, then the pruning must be such that a proper balance will be maintained. Pruning under such circumstances should prob- 
ably be considerably heavier in order to reduce the amount of water lost through evaporation, and to maintain a relatively higher proportion of nitrogen to the carbohydrates present or being manufactured, than if there were available an adequate supply of soil moisture and nitrogen.

In the same way, cultivation, irrigation, and fertilizers affect the pruning practice by limiting or increasing the amounts of soil moisture and available minerals, especially nitrogenous compounds.

\section{NEW WOOD NECESSARY FOR FUTURE F'RUITFULNESS}

As previously suggested, the amount and character of the new wood produced during any season may be taken as an index of the conditions existing within the tree. The amount of new vegetation necessary to maintain the correct balance apparently differs with the species in question. In general, it may be said that those fruits, such as the peach, which bear the bulk of their crop on one-year wood, associate fruitfulness and a relatively greater amount of new growth than seems necessary with spur producers. In the case of spur producers, those species which have the longest lived spurs apparently need the least amount of new wood. This seems reasonable, since at least a portion of such new growth must be used for replacement of fruit-wood which has outlived its usefulness. The amount of new growth necessary for continued fruitfulness may vary from a few inches, in the case of such fruits as the apple and pear, to from two to four feet in the case of the peach.

TABLE 1

Desirable Amounts of New Growth for Bearing Trees

\begin{tabular}{|c|c|c|}
\hline Fruits & Under 10 years of age & Over 10 years of age \\
\hline Peaches..... & 20 to 40 inches & 12 to 30 inches \\
\hline Apricots............. & 12 to 30 inches & 10 to 24 inches \\
\hline Plums (excepting prunes) and Quinces.......... & 10 to 24 inches & 9 to 18 inches \\
\hline Almonds, prunes, apples, pears, cherries..... & 9 to 18 inches & 6 to 10 inches \\
\hline
\end{tabular}

\section{BULK VERSUS FINE PRUNING}

The question may well be asked whether or not pruning should consist in a few large or many small cuts distributed well over the tree. Horticulturists are generally of the opinion that the immediate influence of a pruning cut does not extend far from the place it is made and that, therefore, it is desirable to distribute the pruning 
over as large a portion of the tree as is economically possible. course the total amount of cutting done does eventually produce an influence throughout the tree as a whole.) Whether the cuts should average one-fourth inch, one-half, or one inch in diameter, very largely depends upon the species under consideration. In the case of the peach, where the bulk of the fruit wood must be renewed annually, many cuts must be made in order to secure a large number of new shoots well distributed. With those species producing on spurs, however, a comparatively few cuts may often suffice.

Bulk pruning by the removal of relatively large limbs commonly gives rise to numerous water-sprouts. These may at times be utilized in rebuilding the framework of the tree and a few of them, under favorable conditions, may be converted into a part of the fruit-spur system. Generally speaking, however, these growths are of little value and should be removed entirely as soon as they appear.

\section{SPUR PRUNING}

Spur pruning is essentially "fine" pruning and is often utilized in the rejuvenation of orchards which, for one reason or another, have fallen into class 4 (page 11). It consists in the removal of whole spurs or of portions of spurs, and tends to stimulate vegetative growth. On account of the labor cost involved and the fact that most trees are very "brushy," comparable results are usually secured by a somewhat "coarser" method of cutting.

\section{TRANSITION FROM NON-BEARING TO BEARING}

The lighter the pruning of young trees, consistent with the securing of a proper framework of scaffold branches, the greater will be their development and the sooner profitable crops will be produced. The more severely young trees are pruned, the longer they remain unfruitful. Continued heavy cutting not only reduces the chances for a fruit crop, especially with spur producers, and very materially reduces wood development (fig. 5 and fig. 6), but it also tends to move such trees from class 2 into class 1.

It is a matter of common experience that with fruit trees which are just beginning good production, it is possible by injudicious heavy cutting during one season so to disturb the delicate balance between wood growth and fruiting that profitable cropping is delayed as much as three or four years. The best judgment must always be exercised when determining the pruning treatment to be given any particular orchard; this is especially true when the trees are just approaching the bearing age. 
As the trees become older and bearing is fully established, many instances will doubtless arise in which heavier pruning will be necessary in order to continue regular bearing and to maintain the necessary wood growth at the same time. To this end supplementary fertilization may be advisable or even necessary.

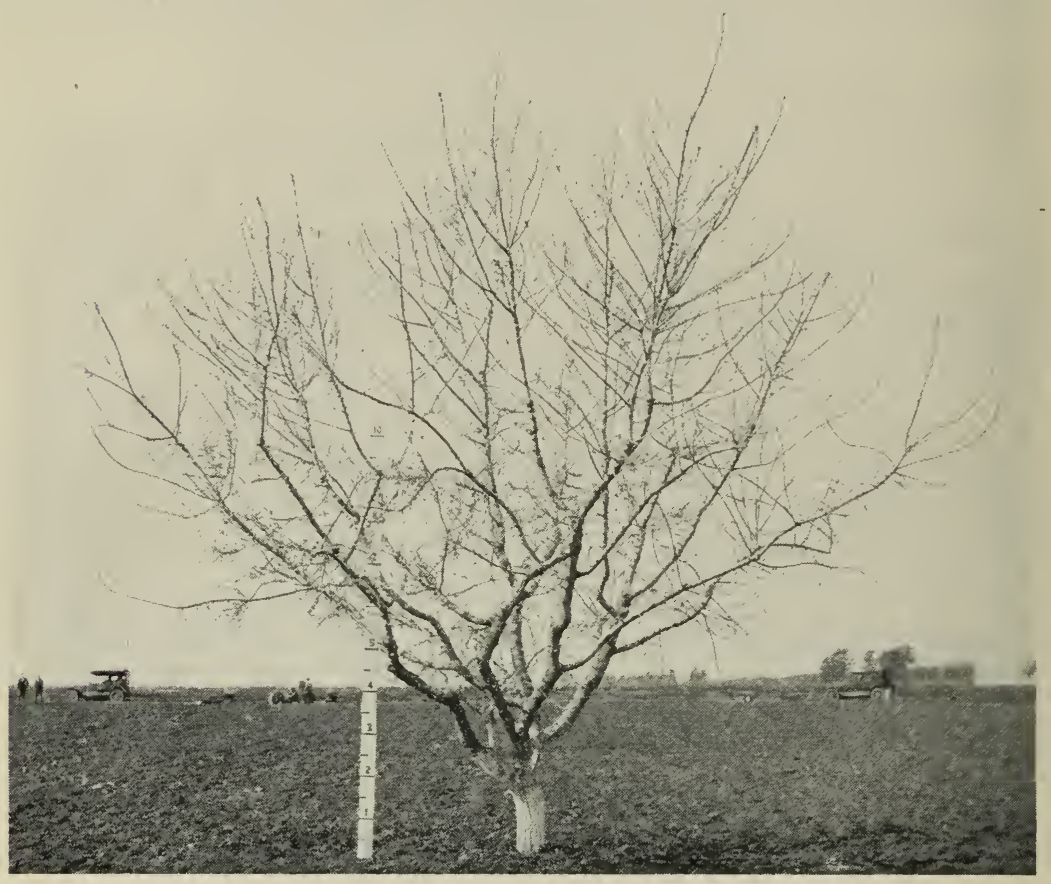

Fig. 5.-Five-year-old Nonpareil almond tree after pruning. This tree has been lightly pruned each year. Compare figure 6 of an adjoining tree which has been severely pruned annually. Note relative sizes of trees and branches. Photographed at same distance as tree shown in fig. 6 . With the exception of the pruning, these trees have received identical treatment. This tree is a representative specimen of a large number of trees similarly treated.

\section{PROMOTION OF FRUITFULNESS}

Distribution of Fruiting Wood.-Pruning is of value in distributing fruiting wood uniformly throughout the tree, thus securing greater tonnage of better quality. By this means, the trees are kept within bounds and the costs of maintenance and harvesting are reduced.

Fruit-Bud Formation.-Sufficient light in all fruit producing parts of the tree is essential in order to secure a uniform distribution of 
fruit-buds. Pruning is practically the only means of securing favorable light distribution. (See also page 18.)

Although fruit-buds for any crop begin their development the previous summer (June to August, under practically all California conditions), nevertheless, the pruning of bearing trees at that time is of doubtful value as a means of securing greater fruitfulness. This point will be discussed later in more detail (page 18).

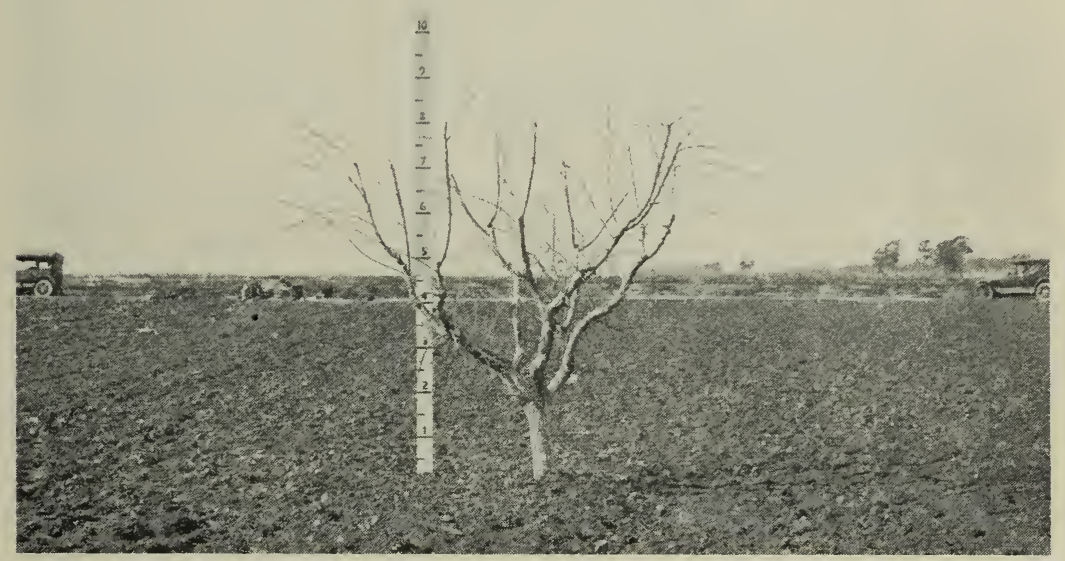

Fig. 6.-Five-year-old Nonpareil almond tree after pruning. This tree has been heavily pruned each year. Compare fig. 5 of an adjoining tree lightly pruned. Note relative sizes of trees and branches. Photographed at same distance as tree shown in fig. 5. This tree is a representative specimen of a large number of trees similarly treated.

Regular Pruning.-Optimum results are obtained only when the pruning treatment is consistently and regularly carried out over a period of years. It is possible with some species to allow the trees to remain unpruned for several years, but the net returns from such treatment are smaller than those secured from annual cutting which insures a constant renewal of fruiting wood. Pruning should be part of each season's operations even though the amount of wood removed in some instances may be comparatively small.

New Wood and Size of Fruit.-There is apparently a direct correlation between new vegetative growth and size of fruit. Trees which make a satisfactory wood growth usually bring the fruit crop through with larger sizes than do those which are unsatisfactory in this respect. It is the common experience of fruit growers that relatively young, vigorously growing trees nearly always produce fruit of large size. 


\section{REGULATION OF SIZE AND QUALITY OF THE FRUIT CROP}

Fruit trees normally tend to produce more fruit than can be successfully carried through to maturity, hence, it has become an established orchard practice to reduce this burden somewhat at the annual dormant pruning. On account of certain fruiting habits, danger from spring frosts, liability to the "June drop," and other factors which may decrease the final crop, it is not feasible to attempt to do all the thinning of fruit with the pruning shears. In order to reduce by any pruning system the number of fruits set so that there will exist no necessity for hand-thinning, it is necessary to limit the crop produced to less than that which the trees can successfully mature. Such severe pruning as this requires, will moreover be inimical to future productivity.

Color of fruit is one of those characteristics difficult to define, which with size, finish, and flavor, constitute "quality." Light is of prime importance in securing color, but if the tree is rightly "opened up" by pruning, little difficulty will be experienced in this connection. In attempting to secure good color by allowing light to penetrate to the interior of the tree, care must be exercised that the scaffold branches are not exposed to the direct rays of the sun, as this would result in sunburn and in subsequent decay of the wood. Likewise, the new growth must be sufficient to shade the fruit and protect it from sunburn, especially in the dry, hot interior valleys.

\section{WHEN TO PRUNE}

The old axioms of "prune when the knife is sharp," and "summer prune for fruit and winter prune for wood," are an unsafe guide and the fruit grower should have a more reasonable basis for his pruning practice.

The general statement may be made that for all deciduous orchards in California, pruning gives the best results when done during the dormant season, after leaf-fall and before new growth starts the following spring.

It has frequently been argued that to increase fruitfulness, trees should be pruned in the summer just before fruit-bud formation in order that the buds which remain may have available all the nourishment which otherwise would be more or less evenly distributed over the entire top.

Such a line of reasoning is fallacious because the leaf area is just as important in the nutrition of fruit-buds as is the root system, and 
to remove a large portion of this manufacturing area just as the tree is beginning to store food (page 10) robs the plant to that extent, and at the same time may start new growth which will also take additional food materials.

In order to determine the influence of summer pruning at the time of active fruit-bud development, forty-eight Muir peach treesthree rows of sixteen trees each-planted in February, 1912, and rather severely thinned and headed in February, 1913, 1914, 1915, and 1916, were pruned as follows between August, 1916, and August, 1920 :

Row 1.-Thinned and headed moderately in February of each year-dormant season. (No summer pruning.)

Row 2.-Thinned moderately in early August each summer. Headed moderately in February each winter, thus rendering trees in this row similar in height to trees in rows 1 and 3. (Moderate summer pruning.)

Row 3.-Thinned and headed moderately in early August each summer and when necessary the older wood thinned out in winter. (Heavy summer pruning.)

Considering the average yield to the tree of the sixteen trees in row 1 as 100, the production for row 2 and row 3 was that indicated in Table $2 .^{3}$

\section{TABLE 2}

Average Yield of Muir Peach Trees With and Without Summer Pruning

\begin{tabular}{|c|c|c|c|}
\hline Year & $\begin{array}{c}\text { Row } 1 \\
\text { Winter Thinned } \\
\text { Winter Headed }\end{array}$ & $\begin{array}{c}\text { Row } 2 \\
\text { Summer Thinned } \\
\text { Winter Headed }\end{array}$ & $\begin{array}{c}\text { Row } 3 \\
\text { Summer Thinned } \\
\text { Summer Headed }\end{array}$ \\
\hline $1917 .$. & $100-(51 \mathrm{lbs})$. & $133-(78 \mathrm{lbs})$. & $98-(50 \mathrm{lbs})$. \\
\hline 1918. & $100-(43$ lbs. $)$ & $158-(68$ lbs. $)$ & $128-(55$ lbs. $)$ \\
\hline $1919 .$. & $100-(203$ lbs. $)$ & $100-(204$ lbs. $)$ & 67-(136 lbs.) \\
\hline $1920 .$. & $100-(116$ lbs. $)$ & $115-(134$ lbs. $)$ & $90-(104$ lbs. $)$ \\
\hline Total... & $100-(413$ lbs. $)$ & $117-(484$ lbs. $)$ & $83-(345$ lbs. $)$ \\
\hline
\end{tabular}

During the season of 1919 the crop from row 2 did not appreciably exceed that from the trees receiving only a moderate winter pruning. The increased yields in row 2 during the other years were due perhaps to admission of sunlight to the interior and lower portions of the

3 The difference recorded in Tables 2 and 3 are perhaps not statistically significant, but since the tendencies shown are exactly in accord with the results of other experiments and with observations extended over many years, it seems desirable to include these data. The reader should realize, however, that any figures presented in connection with experiments with plants merely indicate general tendencies rather than exact responses because of the great variability within the plants themselves and of the conditions under which they grow. 
summer pruned trees with consequently more economical manufacture and storage of carbohydrates throughout a larger portion of the fruiting area. Row 3 was materially weakened by the rather heavy summer pruning.

Development of Trees.-That summer pruning of the Muir peach as practiced in these experiments is devitalizing is shown not only by the trees themselves, but also by measurements of the trunks, which seem a fair indication of both root and top development.

It has been shown ${ }^{4}$ that trunk circumference measurements may be confidently depended upon as a reliable index of the total development of the young tree, both root and top. It will be seen from the figures presented below that summer pruning may lessen the chance for future crops by limiting tree growth.

TABLE 3

Average Trunk Circumference of Trees

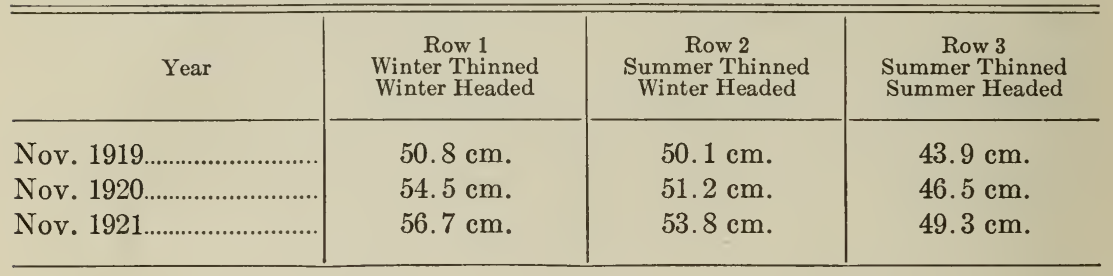

\section{PRUNING SYSTEMS}

In recent years there has been much discussion in California regarding the relative merits of the so-called "long" and "short" pruning of deciduous fruit trees. It is rather difficult to draw a definite line of demarcation between these two systems because with their modifications they merge into each other.

Briefly, it may be said that the system of "short" pruning consists essentially in a more or less severe thinning out, accompanied by a heavy heading of the new growth; while the system of "long" pruning consists essentially in a moderate thinning out and in keeping the tree within bounds by cutting to laterals which are left untouched. The latter system removes somewhat less wood, but the conclusion of many growers that it really amounts to little or no pruning is incorrect.

There has been a tendency throughout the state towards less severe pruning so that it is now becoming increasingly difficult to distinguish

4 Tufts, W. P. Influence of heavy and light pruning upon the growth of deciduous fruit trees. California State Dept. Agr. Mo. Bull. 8: 529-535, figs. 139-140. 1919. 
between orchards, which are "short" and those which are "long" pruned. Thoughtful and observing orchardists are beginning to realize that the same principles of plant growth and response apply with equal force to all systems of pruning and as their idea of the relation of vegetative growth, tonnage, quality, and economy of orchard management become clearer they will realize that the different systems at present in use merge into each other, and that the best system for any particular case will lie at some point between the extremes of "short" and "long" pruning.

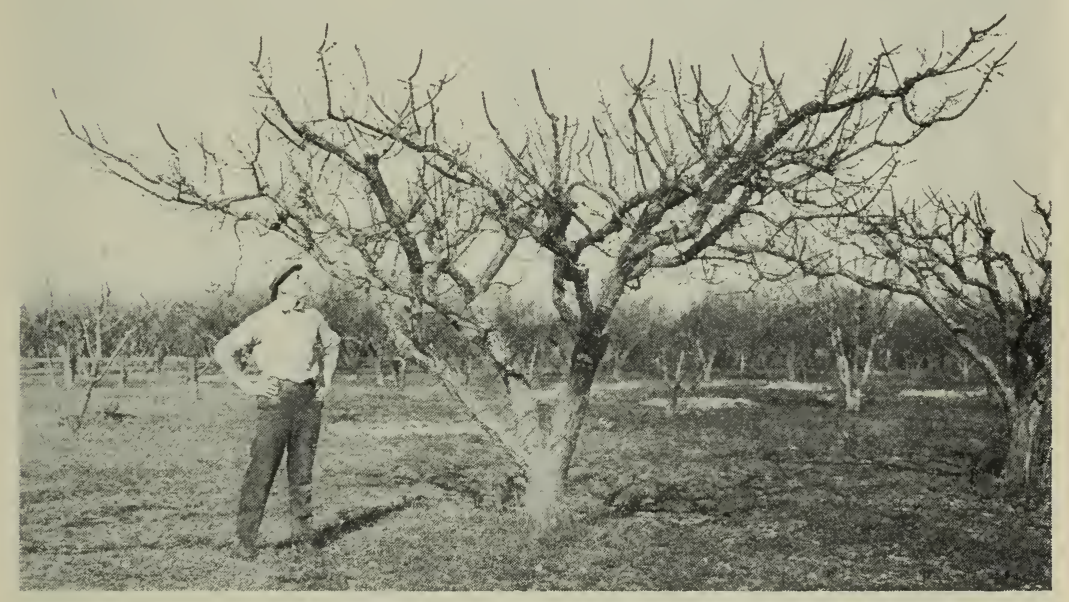

Fig. 7.-Winters System of apricot pruning. Note low spreading top and severity with which new shoot growth has been headed.

Mention should be made of several modifications of the so-called short and long systems of pruning at present in vogue in certain sections of California. Undoubtedly many growers who are following in all essential details one of these methods may differ as to the classification here made.

Figure 7 shows an apricot tree trained by the so-called "Winters System" (sometimes aptly referred to locally as the "Wolfskill Hack"). This flattened expanse of the fruiting area is designed to give better exposure to the sun with the object of ripening the fruit earlier. It does not bring about the result desired, however, because the heavy cutting gives rise to succulent vegetative growth early in the season, the shade from which more than offsets the advantage of 
a flat head. In a test ${ }^{5}$ conducted in the Winters district, in 1919, trees pruned by thinning produced larger and earlier crops than comparable trees pruned by the standard "Winters System." This method of training is also objectionable in that the upper sides of the main branches are very often badly sunburned which results in wood decay, even though the vegetative growth is sufficient to shade the fruit and retard its development. Moreover, restricting the height of the tree

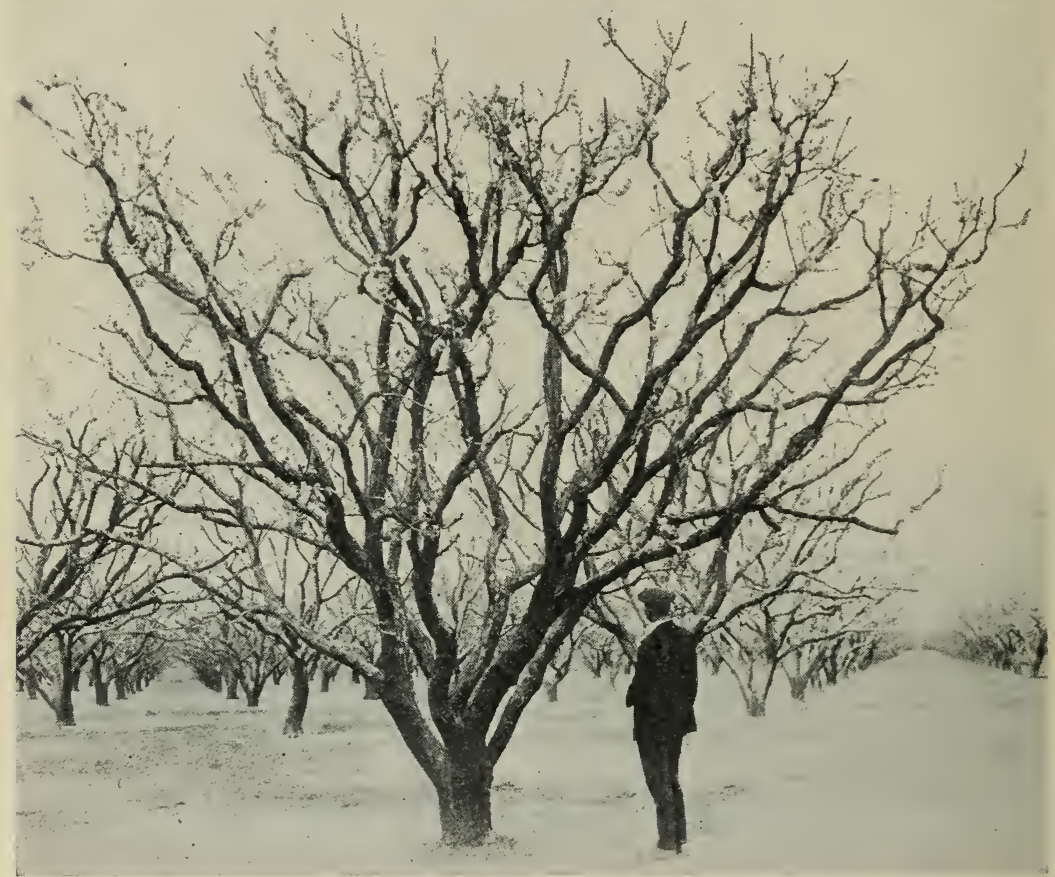

Fig. 8.-Mature Blenheim apricot tree pruned by the so-called "short", system which consists essentially in a severe thinning out and heading back of new wood growth. Note lack of fruit-spurs in lower parts of tree due to shading out. Too many main scaffold branches.

so that all work is done from a six-foot ladder materially reduces the fruiting area and the possible tonnage of fruit of high quality.

Figures 8 and 9 show another system by which deciduous tree fruits are pruned in California. This method is very generally applied and consists essentially in a heavy thinning, accompanied by the removal of all but three or four buds on the shoots which are headedan example of the so-called "short pruning."

5 Tufts, W. P. Why prune bearing apricot trees heavily? California State Dept. of Agriculture Mo. Bull. 8: 15-22, figs. 10-17. 1919. 
Certain growers have worked out for their own conditions quite satisfactory systems of training and pruning which are distinct departures from the ordinary methods.

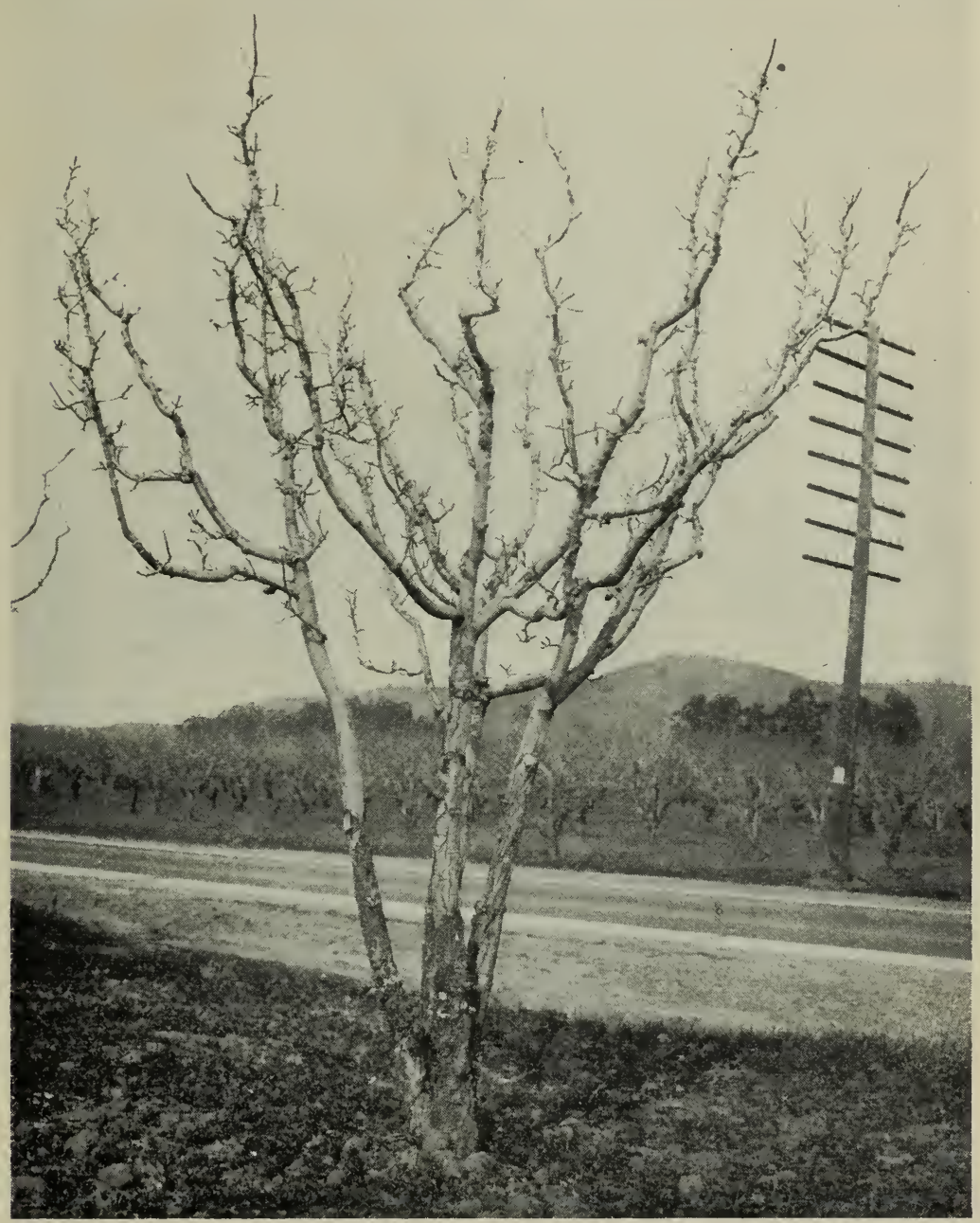

Fig. 9.-Fifteen-year-old Bartlett pear tree typically "short"' pruned. Note severe thinning and heading back. Only three or four buds have been left on each one-year shoot

Figure 10 shows a mature peach tree pruned by the "Sims System." The relatively few, upright main scaffold branches clothed with long, slender fruiting twigs are characteristic of this system. 
The few upright scaffolds are able to hold a heavy load of fruit with the minimum of bracing. The rather narrow spread of trees thus pruned is perhaps an unwarranted restriction of the fruiting area.

One of the most interesting departures from standard pruning practice is the so-called "Caldewell System" of pear pruning (fig. 11).

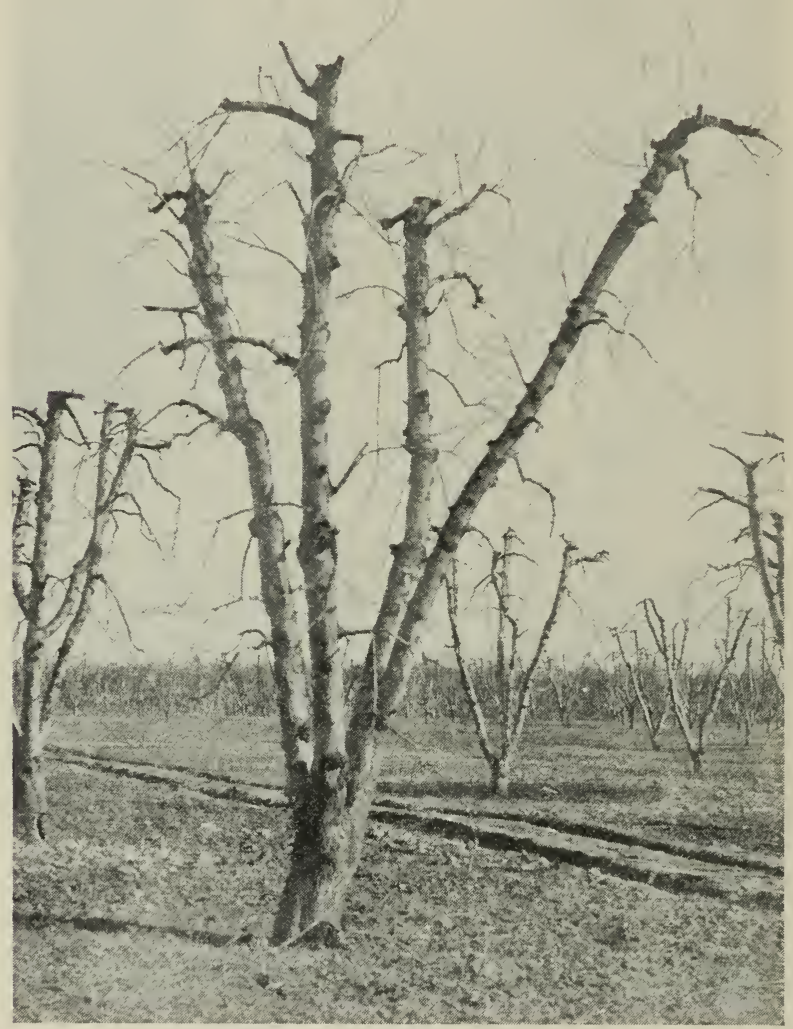

Fig. 10.-Mature peach tree pruned by the "Sims' System." Note heavy framework branches. Fruit is produced on long pendant "hangers.'" By this unusual method much fruit is produced on spurs. Trees after reaching a certain height (12 to 16 feet) are never allowed to grow taller.

Briefly stated, this system consists in the tying down of the upright one-year-old shoots at an angle somewhat below the horizontal. The resultant new growth arises just below and behind the highest point of the bend. Practically all growth beyond this point is reproductive in character and rapidly develops a good fruit-spur system. In prin- 
ciple the Caldwell plan is very similar to the espalier method of training used in Europe. In both cases the bending of the branches seems to induce fruitfulness.

At each dormant season all the new shoots are tied down in such a way that there is as little shading as possible of the lower branches. The later tying is done to any convenient point on either trunk or branch. At ten years of age few pear orchards attain the size and productiveness of Mr. Caldwell's, whose trees, with the exception of the first winter, have not been touched with the pruning shears.

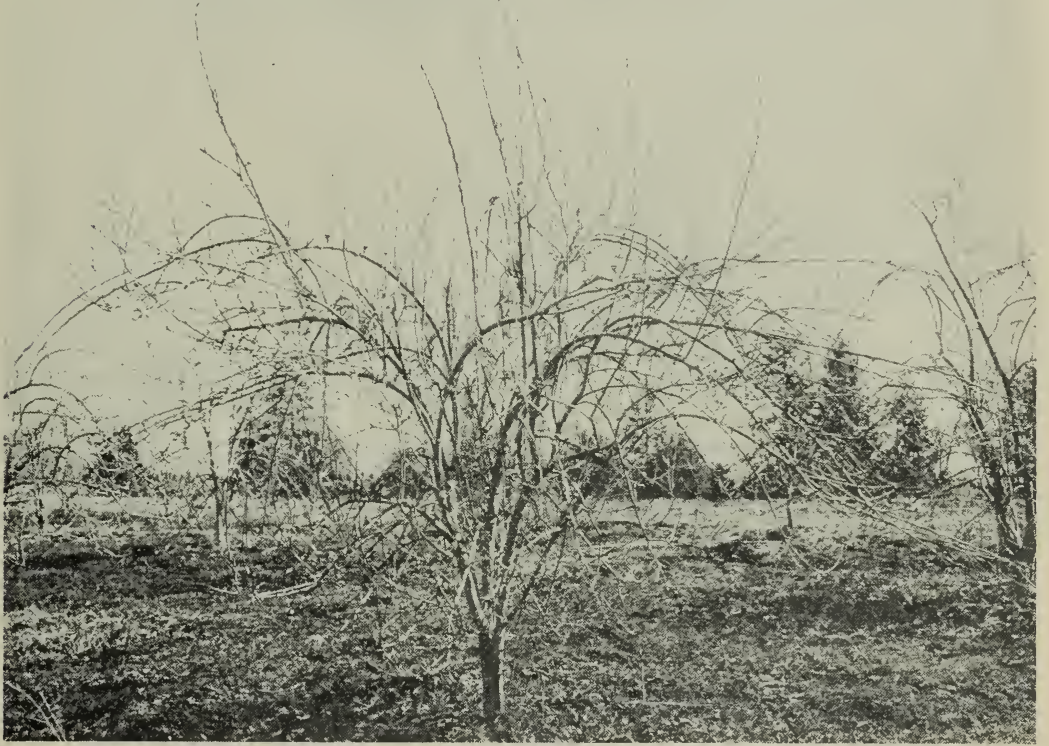

Fig. 11.-Caldwell System of pear pruning. Six-year-old Bartlett pear tree which has been trained by tying down new shoots each year. Note new branches which arise at bend, these will in turn be tied down to a position a little below the horizontal.

Briefly, the advantages claimed for the method are: large trees of good mechanical strength, combined with a large fruiting area close to the ground, are secured in a comparatively short period of years; they come into bearing from two to four years earlier than trees which are trained by severe cutting back; they can be trained to a more shapely form in a windy section or where prevailing winds hinder symmetrical development; and finally, they produce larger crops of equal quality.

The chief disadvantage is that this system to be successful must be part of a comprehensive and intensive orcharding programme. Since 
all wood is conserved, special care must be exercised to see that adequate moisture and fertility are present in order to secure an abundance of new wood and at the same time carry large crops through to maturity and to supply the enormous leaf area which is being increased from year to year. In most soils some renewal pruning will undoubtly be necessary as soon as the trees begin bearing heavily in order

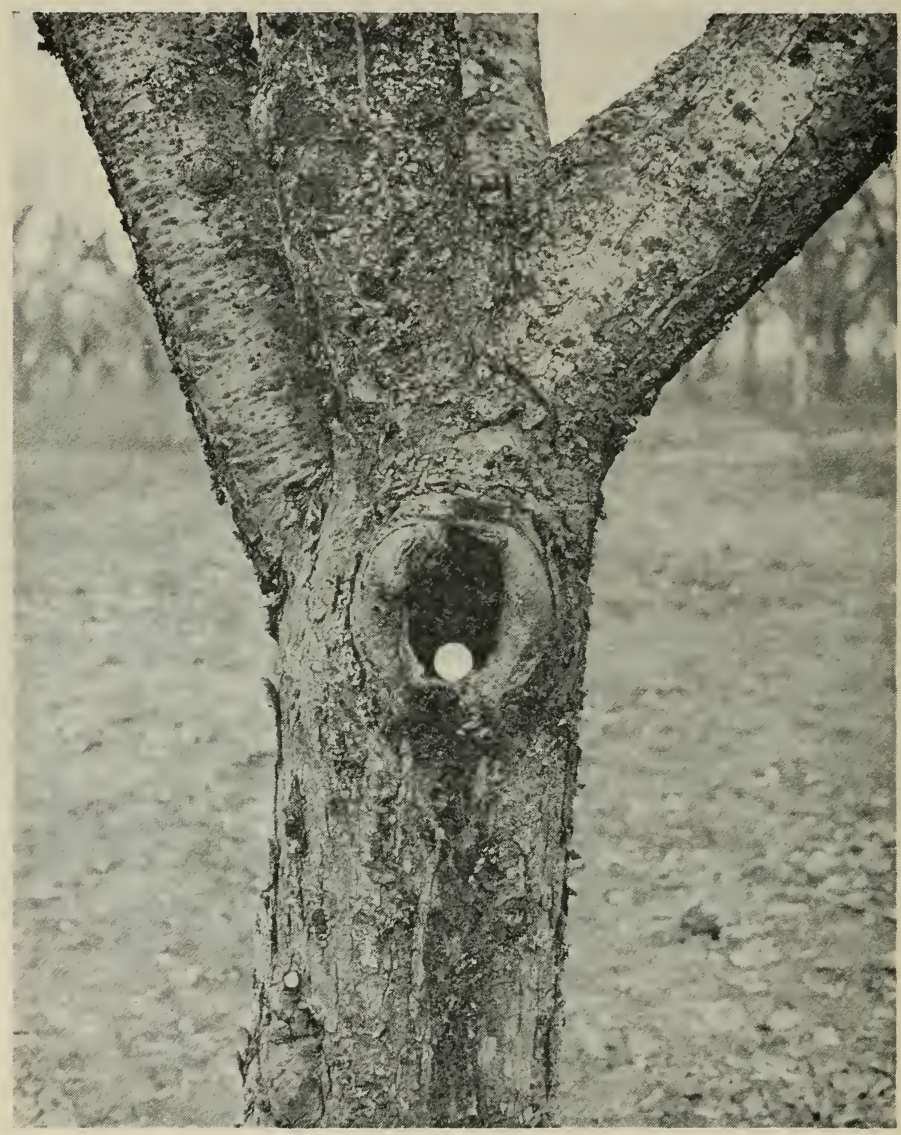

Fig. 12.-A well made pruning cut. Note callus formation which in the course of a few years will completely cover the large wound. Compare size of cut with the quarter-dollar.

to replace the fruiting wood which has outlived its usefulness and to maintain a proper condition of vegetative vigor. Success depends very largely upon the skill and judgment of the individual. The method is probably applicable only to pears and should not be adopted without a full understanding of its requirements and limitations. 
In adopting any pruning system, the first and most important question to be asked is: "Will this method insure the annual production of a good tonnage of fruit of high quality?" The growth of new wood is probably the only index by which the grower can judge whether or not future yields are being sacrificed for the sake of one or two heavy crops. On the other hand, the production of too great an amount of vegetative growth will reduce the yields far below the maximum which can profitably be maintained.

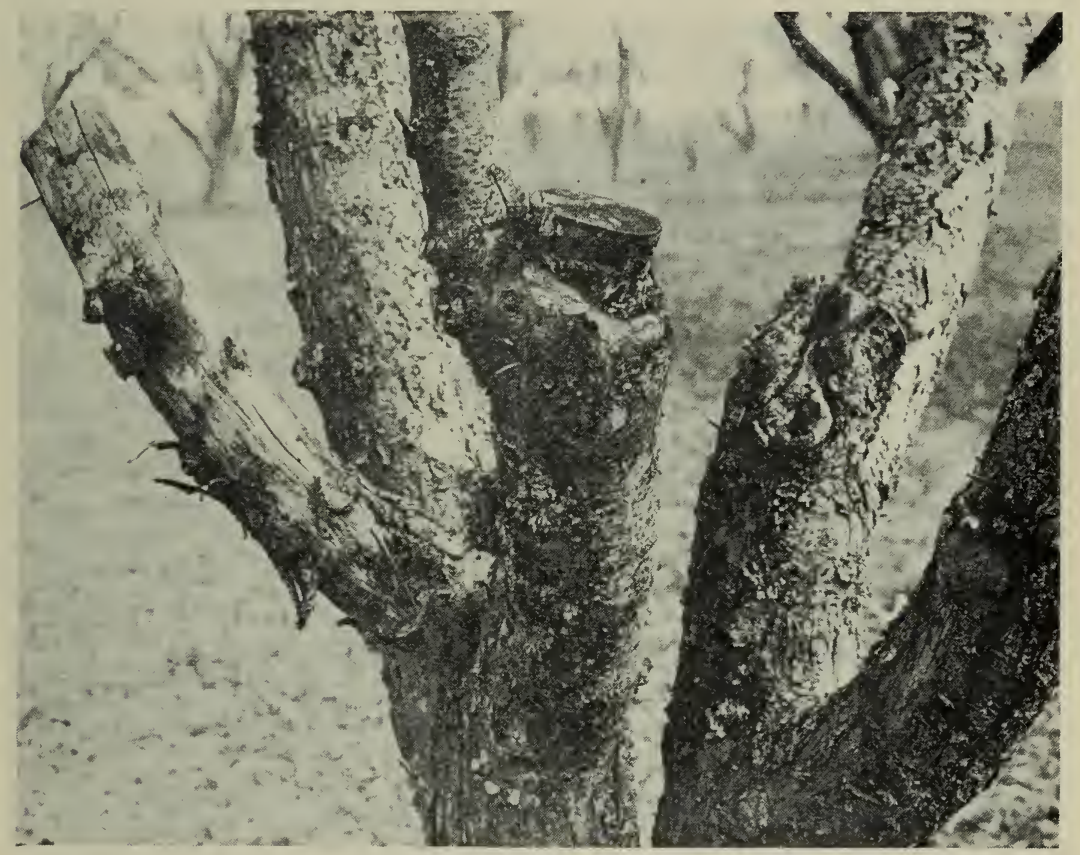

Fig. 13.--Improperly made pruning cuts. Such stubs will never heal over and are a constant menace as affording an entrance to wood rotting organisms.

\section{PROTECTION OF PRUNING WOUNDS}

If a tree is properly pruned from the start, the removal of large limbs can for the most part be avoided.

All cuts should be made close to the branch from which the limb is taken (fig. 12), leaving no stub (fig. 13). This will greatly facilitate the healing of the wounds.

The treatment of pruning wounds depends largely upon local conditions. In any section, like the Watsonville apple district, where the foggy climate favors the germination and growth of the fungi which cause wood decay, it is best to disinfect the pruning cuts as 
soon as the wood has dried a little, but before any cracks have formed. Cyanide of mercury, one part to 1000 parts of water by weight, is a good disinfectant. The solution should not be put into a metal container. Containers made of wood, glass, or enamelware should be used. Cyanide of mercury is a stomach poison and must be handled with care.

In localities where the air is relatively dry, it will ordinarily be unnecessary to disinfect pruning wounds, but in any case large pruning wounds should be covered with some protective substance. This is not to aid the healing, but to prevent the entrance of rot-causing fungi. All wounds an inch and a half, or more, in diameter should be covered.

The following are three of the best materials for covering wounds:

White lead paint mixed with raw linseed oil.

Asphaltum, Grade D, which must be heated before applying.

Oronite, which is similar to asphaltum, but which can be applied cold. When too thick, a special non-injurious "oronite thinner" can be added.

\section{PRACTICAL SUGGESTIONS}

1. The total amount of new growth which the tree makes, taking into consideration the crop produced and the conditions under which it is grown, is the best criterion by which to judge whether or not the pruning has been of the proper severity (page 14).

(a) If the resultant new growth is longer than seems desirable for a tree of the kind and conditions under which it is grown, then the previous pruning was too severe (page 12).

(b) If the new growth has been inadequate the cutting was too light and a heavier pruning programme should be adopted, except in those cases where sparse growth has resulted from non-availability of carbohydrates.

2. The pruning should include adequate thinning out of the fruiting shoots, and this should be followed, where necessary, by a thorough thinning of the fruit (page 18).

3. The tree should be thinned out sufficiently to admit an adequate light supply (page 18).

4. All interfering branches, dead wood, and diseased parts should be removed.

5. The larger limbs should be spaced far enough apart throughout their length so that they will have ample room to develop the desired fruiting branches and spurs. 
6. The trees may be kept from becoming too high by regularly cutting back the tallest branches to strong outward growing laterals.

7. All branches should be cut off close to the limb from which they arise, leaving no stubs (page 27).

8. It should be emphasized at this point that it is impossible to secure an ideal shape, height, and distribution of fruiting wood unless the trees are spaced far enough apart when planted to enable them to develop normally. There has been a decided tendency among California fruit growers to plant their trees too close together for normal development.

\section{TREATMENT FOR THE DIFFERENT FRUITS}

Almonds.-The almond produces its fruit largely on short spurs, although some nuts are found on one-year wood, especially in certain varieties such as the Jordan and California. The fruiting branch of the almond remains economically productive for about five years.

For the sake of economy, the pruning of bearing almonds is usually restricted to the removal of limbs one-half inch to an inch and a half in diameter. Little or no time is spent in thinning out one-year shoots, except for the removal of water-sprouts which are frequently abundant.

This practice is probably satisfactory when the pruning is done annually and conditions are such that it results in sufficient new growth to cause a continual renewal of the fruit-spurs. Approximately one-fifth of the fruiting wood should be replaced each season. Trees under ten or twelve years of age can be expected to make from nine to eighteen inches of new growth over the tree as a whole, while older trees should make from six to ten inches. Many old almond orchards do not make six inches of new growth each year, but it is very probable that the average production would be increased if the pruning were sufficiently heavy to induce this amount. The cutting of trees lacking in vigor should consist of a rather heavy pruning of the type mentioned above together with some cutting back of the tops to large lateral limbs and some thinning of the smaller shoots and fruiting branches.

It may be said that in general the almond tree does not need to be thinned out quite so much as other trees because of the fact that its foliage is rather sparse, and hence light readily filters through the branches. Furthermore, the almond is seldom, if ever, pruned with the idea in mind of preventing overbearing, since it does not produce a crop heavy enough to break any of the limbs and the yield of the tree is of more importance than the size of the nuts. 
On account of the fact that almonds are not picked by hand it is not essential to keep the tree as low as with most fruits. It is well, however, to keep them low enough so that all the nuts can be reached from the ground with a pole not longer than sixteen feet.

On very rich soils with a plentiful supply of moisture, the trees may make an excessive wood growth at the age when they should be coming into bearing. Since pruning, except under conditions where carbohydrates are limiting, is one of the factors which tend to stimulate vegetative growth, the rational procedure in such a case seems to be to stop pruning for a year or two. This will tend to throw the trees into bearing and curb the heavy growth. After the bearing habit is once thoroughly established, pruning may be resumed.

Apples.-Most varieties of apples generally produce fruits terminally on spurs which are found on wood that is two years old or older. The life of an individual apple spur is frequently as much as fifteen or twenty years, but in most orchards the period over which a spur bears sufficiently often to be an important factor in production is not over eight or ten years. Frequently these terminal producing spurs fruit in alternate years. Unfavorable weather conditions may prevent most of the spurs from bearing in a particular year, and as a consequence, a very heavy crop will be produced the next. These trees will very likely then be thrown into the habit of alternate bearing. There are, however, certain notorious alternate bearing varieties such as the Oldenburg, Baldwin and Wealthy, which may firmly establish the alternating habit regardless of weather conditions. In California it very often happens that a spur elongates and sets a terminal fruit-bud during the same summer that it is maturing fruit, in which case the tendency towards alternate bearing is broken. Possibly one of the best methods of circumventing the alternate bearing habit is to keep the trees in such a state of vegetative vigor that only half or less than half of their spurs bloom in any one year.

While the major part of the apple crop is commonly borne on spurs, a smaller portion is produced on one-year wood. This is particularly true of young trees of certain varieties, such as the Gravenstein, Ben Davis, Jonathan and Winesap. Varieties differ as to the part of the shoot on which the fruit is developed. Normally, the fruit-buds are borne either terminally or laterally near the apex. Varieties that produce an abundance of fruit-buds on the one-year wood usually come into bearing at an earlier age and are more likely to bear annually than those that fruit entirely on spurs.

A thinning out of the branches to admit sufficient light to penetrate to all parts of the tree is a prime consideration in causing new spurs to develop and in aiding those that already exist to bear regularly. 
Many varieties of apples tend to over-bear, especially in the alternate years, and as a result the fruit requires a great deal of handthinning. The type of pruning that will encourage annual bearing and reduce the amount of hand-thinning that is necessary is that which tends to reduce the crop somewhat and to invigorate the trees in the alternate years when they have a heavy set of fruit-buds. This may be done not only by thinning the shoots and branches, but also by thinning out the spurs, and renewing the long, much branched ones by removing the older parts of the spurs and saving the newer, i.e., by "spur pruning." The pruning particularly in reference to the fruitbuds and spurs, should be much lighter the following year, when the tree has comparatively few fruit-buds.

In general, the apple does not require heavy pruning. On account of its habit of bearing largely on long-lived spurs, approximately only 10 per cent of which must be replaced each year, it requires somewhat less new wood growth than some other fruits. The young bearing apple tree should ordinarily make from ten to twenty inches of new wood growth each year, while with the older trees six to ten inches is sufficient. This amount of new wood growth can ordinarily be secured by cutting back to laterals, leaving a few of the one-year-old shoots intact. However, if the wood growth shows a tendency to drop below the above mentioned minimum amounts, heading back the laterals which are left after thinning may be necessary to secure the proper vigor.

A thorough thinning out of the tree is of special importance in the case of varieties having red fruit, as highly colored apples are the result of abundant light supply throughout the tree. While it has been stated that in general summer pruning does not seem desirable for bearing trees, it is possible that a light summer thinning may be beneficial in securing a better color of the fruit on trees of red varieties, having foliage which is rather thick and dense.

The apple powdery mildew (Sphaerotheca leucotricha (Ell. \& Ev.) Salm.) which has done considerable damage to the apple orchards in California, particularly in the humid coastal regions, can be largely controlled by proper pruning in conjunction with spraying. The pruning treatment in this respect consists in removing the diseased shoots and spurs at the regular dormant pruning, and thus eliminating the sources of hold-over infection. Mildewed shoots are easily recognized by their gray or silvery appearance.

The undesirability of removing large limbs has already been pointed out (page 27), but it must be emphasized again that it is especially dangerous to cut off main branches in damp coastal dis- 
tricts, such as the Pajaro Valley. When limbs more than an inch and a half in diameter are removed it is very probable that a serious woodand-bark disease, known locally as "sappy bark," will develop. The serious nature of the malady will be apparent from the fact that it often travels down the limb from a large wound and eventually reaches the trunk and kills the tree. Disinfecting and painting the wounds has not as yet proved effective in preventing the disease.

Apricots.-The apricot produces the bulk of its fruit laterally on spurs which generally do not live more than three years. A relatively small portion of the crop is produced laterally on one-year shoots.

Since the fruit-spur system of the apricot is short-lived, the pruning treatment must be such as to cause its continual renewal. Young bearing apricot trees should make from fifteen to thirty inches of new growth each year. On older trees the desirable length of new growth ranges from ten to twenty-four inches. The peach and Japanese plums are probably the only fruits that ordinarily require a heavier pruning than the apricot in order to produce sufficient new growth for continued profitable production.

\section{TABLE 4}

Yield of Six-Year-Old Royal Apricots, 1922

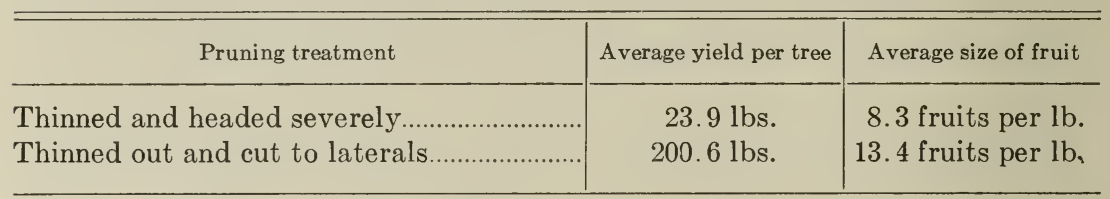

Particular pains should be taken not to allow the branches to become too long, willowy and unbranched. This condition can best be avoided by cutting back to laterals. As the tree becomes older and only a short growth follows a thinning system of pruning, it is quite possible that a more severe type of cutting will have to be used to maintain the vigor of the tree.

The apricot is one of the fruits which has in the past in California been very commonly subjected to heavy pruning regardless of the age and vigor of the trees. The yield record of a six-year-old Royal apricot orchard given in Table 4 is interesting in this connection. The orchard was planted at the University Farm at Davis in February, 1916. It is growing on a sandy loam of the Yolo series and all trees have received the same good, uniform, commercial culture except as regards pruning treatment. In each case the figures are the average of sixteen trees in a single block receiving the same pruning treatment. 
These figures bring out very strikingly the influence of heavy and light pruning on young bearing apricot trees.

As the tree becomes older, the continuance of a comparatively light system of pruning, especially in the absence of adequate soil moisture, will usually result in a slowing down of wood growth and a consequent falling off in yield.

This fact is rather clearly demonstrated in Table 5, which shows the yield records over a series of years for a block of fifteen Tilton apricot trees, five trees to a treatment. ${ }^{6}$ The trees in question were all planted in the University orchards at Davis in March, 1908, and were thinned out and headed severely from 1909-1915 inclusive, the pruning experiment starting the next year. With the exception of the pruning, these trees have received identical cultural treatment.

TABLE 5

Average Yield of Tilton Apricot in Pounds per Tree

\begin{tabular}{|c|c|c|c|c|c|c|c|c|}
\hline Pruning treatment & 1916 & 1917 & 1918 & 1919 & 1920 & 1922 & 1923 & Average \\
\hline $\begin{array}{l}\text { Thinned and headed se- } \\
\text { verely...................................... }\end{array}$ & 23 & 59 & 50 & 88 & 30 & 53 & 58 & 52 \\
\hline 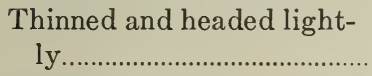 & 20 & 119 & 107 & 169 & 252 & 241 & 74 & 140 \\
\hline Thinned out only.............. & 77 & 171 & 146 & 137 & 172 & 214 & 107 & 146 \\
\hline
\end{tabular}

It will be observed that the lighter pruning resulted during the very first year in a marked increase in yield over that obtained from the trees headed back. The greater yield of the thinned trees was due to the production of fruit on the one-year wood, which was removed from the trees which received a heavy or light heading. The comparatively low yield of the trees during this year is very largely accounted for by the fact that these trees had been accorded a very heavy cutting from the beginning with consequent shading out of all fruit spurs by the denseness of the vegetative growth thus secured.

For the first three years the yields were approximately inversely proportional to the severity of the pruning. By 1919 the results of the lighter pruning and heavier fruiting were evidenced by the larger yield of trees which were lightly headed, and for the following two seasons the trees receiving this treatment retained this lead. This was naturally to be expected in view of the decreased wood growth on

6 It is realized that the number of trees included in each plot is too small to give the data statistical reliability; nevertheless the figures are presented since they bear out the author's observations in hundreds of California orchards. It is not intended that the yields and sizes in any of the tables should be taken as an exact measure of the results obtained, but merely as showing tendencies. 
the very lightly pruned trees which had no way of renewing their fruit-spur systems. There was no crop in 1921 on account of killing frosts.

The heavily headed trees matured their crop from a week to ten days later than those which received only a light heading or simply a thinning treatment. This fact is of significant importance in those sections where the fruit is primarily intended for eastern shipment.

Although the fruit was slightly larger on the severely pruned trees, the size has been entirely satisfactory in the other treatments as may be seen from the following average for a six-year period. However, the fact should be recognized that in some sections of the state and especially with older trees very light pruning may result in fruit of inferior size.

TABLE 6

Average Size of Fruit Per Pound-Tilton Apricot, 1916-1922

\begin{tabular}{|c|c|}
\hline Pruning treatment & Average size of fruit \\
\hline Thinned out and headed severely. & \multirow{3}{*}{$\begin{array}{l}8.9 \text { fruits per lb. } \\
10.7 \text { fruits per lb. } \\
10.8 \text { fruits per lb. }\end{array}$} \\
\hline Thinned out and headed lightly..... & \\
\hline Thinned out only & \\
\hline
\end{tabular}

These data lend further weight to the argument that it is necessary to maintain the vegetative activity of the bearing fruit tree if continued profitable production is to be secured. Under conditions existing in this part of the University orchards, where no irrigation facilities were available, it is quite evident that it was impossible to maintain a proper balance between fruit production and wood growth by a reliance on a thinning out system of pruning unaccompanied by heading. In other words, lack of irrigation brought about a depletion of soil moisture which either killed a certain number of roots or rendered them for the time being incapable of functioning thus reducing the feeding area and destroying the balance between carbohydrates and available mineral nutrients, which is necessary for the best production of fruit.

In sections which are subject to the ravages of the brown rot (Sclerotinia cinerea (Bon) Schrot.), efforts should be made to remove all infected spurs and shoots, as these continue to produce spores of the fungus throughout the winter and spring and make control by spraying more difficult.

The pruning of trees infected with bacterial gummosis (Bacterium ccrasi Griffin) warrants special mention. This disease is characterized by gumming cankers on the trunks and larger limbs during the winter 
and spring months, and if not carefully and promptly treated may girdle the affected parts and cause their death. The disease is caused by bacteria and may be readily spread from one tree to another by pruning tools. In case this malady is known to exist in an orchard, it is a wise precaution to disinfect the shears and saw used in pruning after finishing each tree. A solution of bichloride of mercury, one part by weight to 500 parts of water, is a satisfactory disinfectant. If the solution is to be used for treatment of the cankers as well as for a disinfectant for the tools, it should contain also cyanide of mercury one part by weight to 500 parts of water.

Sweet Cherries.-Sweet cherries are borne laterally on long-lived spurs which are economically productive for ten or twelve years. On account of this persistence of the fruit-spur system, the sweet cherry needs less renewal wood than practically any other deciduous fruit. If the trees have been properly trained and brought into bearing, but little pruning is necessary to maintain them in a productive condition. That pruning which is necessary, however, should be done annually and should be of sufficient severity to renew approximately ten per cent of the fruit bearing area each year.

It is characteristic of the sweet cherry tree to produce most of its new growth from terminal buds. There is, therefore, a decided tendency to develop long pole-like branches if no heading is done. It is usually considered necessary to cut back cherry trees moderately the first four or five years, or until such time as the framework is completed. After the first few years, the further heading will cause delay in fruiting, and the desired form can generally be attained without resorting to this practice. The cherry is slow in coming into bearing and just as long as new wood growth is encouraged by rather heavy cutting, the tree will make only shoot growth and fail to develop fruit-spurs.

As the sweet cherry tree is naturally upright in growth, care should be taken to give it as much spread as possible by retaining the outward growing shoots and removing the upright ones. This is of special importance with such upright growing varieties as the Lambert and Black Tartarian. The Napoleon (Royal Ann) naturally assumes a spreading habit with age. Certain cherry growers have had considerable success in keeping their trees low by very little if any pruning during their earlier years, thus forcing them into rather precocious fruiting and allowing the weight of the crops to bring about the desired spread. Careful judgment, however, must be used in adopting such a plan. 
The cherry tree is very particular as to the conditions under which it will thrive. It is particularly susceptible to drought and excessive soil moisture. The reinvigoration of weak trees is a more complicated problem than the mere adoption of a rational pruning method. In order to keep a bearing cherry orchard in a good state of vigor, particular emphasis must be laid on proper soil conditions. When it is found necessary to cut back cherry trees into older wood, either for the purpose of lowering the trees or of stimulating the wood growth, care should be taken to cut to a lateral, wherever possible. Trees showing much die-back of the leading branches can sometimes be rejuvenated by rather severe pruning. However, it should be mentioned again that soil conditions must at the same time be improved.

The sweet cherry, like the apricot, is susceptible to bacterial gummosis. Suggestions regarding the handling of apricot trees suffering from this disease apply with equal force to cherries.

Peaches and Nectarines.-The fruiting habit of the nectarine is practically identical with that of the peach.

There is probably no other fruit which responds to proper pruning and which declines with neglect so readily as the peach. This behavior is largely explained by the fact that the peach bears its crop almost entirely on one-year-old wood. Only occasionally is fruit found on spurs, and these are very short-lived. For this reason it is necessary to prune peach trees more heavily than most other fruits in order to produce sufficient fruit-bearing wood each year. Twenty to forty inches of growth over the tree as a whole is not excessive for young bearing trees. Older trees may be expected to produce each season an abundance of shoots of from twelve to thirty inches in length.

It is characteristic of the peach that its bearing area is carried higher and higher each year, leaving long stretches of non-fruiting branches that are subject to sunburn and decay and that serve only as a connection between the fruiting periphery of the tree and its sources of water and mineral nutrients - the roots. The denseness of the foliage of the peach makes it difficult to maintain a satisfactory distribution of the fruiting wood in the interior of the tree. Care must be taken to see that the trees are thinned out in order that adequate light may reach all parts and thus insure the production of fruiting branches on the lower limbs. If careful attention is not given to this detail then the characteristic "leggy" peach tree with sunburned branches and practically all new growth confined to the periphery is the result.

Hanging shoots and branches, sometimes spoken of as "hangers," are particularly desirable for fruit bearing on peach trees and should 
be encouraged. Care should be exercised, however, to see that these do not become too long by the addition of a certain amount of growth each year. Such shoots can frequently be shortened and renewed by cutting back to a new lateral. Fruit on these hangers is borne on relatively short annual growths and sometimes on spurs.

In California it is seldom that a peach tree fails to set enough fruit-buds for a heavy crop. In fact, one of the most perplexing problems in the pruning of bearing peach trees is to determine what amount of fruiting wood should be left to blossom and mature fruit. After the trees have been thinned of the superfluous larger branches and the desired form has been secured, the question arises as to how best to reduce the fruit-buds to such a number that the crop which is likely to set will be well distributed and at the same time will not impose too heavy a task at the thinning season. Generally speaking, it is more economical to reduce the crop as much as possible with the pruning shears during the dormant season than entirely by hand thinning after the fruit is set. However, to attempt to thin with the pruning shears so that no hand-thinning will be necessary to secure the desired size and quality is likely to reduce the total tonnage to such a degree that the practice will not be economical.

This reduction of the fruiting wood may be accomplished either by a thinning out and heading back or a combination of these two methods. Care must be taken not to head the new shoots on varieties which bear only at the tip or on the outer half of the shoot, especially, when the set of fruit-buds is light. This method of fruiting is characteristic of such varieties as the Tuscan and Phillips Cling peaches. On the other hand, the Elberta, Muir, Alexander, Early Crawford, and Lemon Cling are typical of the varieties that bear rather uniformly throughout the entire length of the shoot. With the latter varieties, heading of the fruiting twigs may be entirely feasible and in fact desirable.

In most instances the proper amount of fruiting wood should be obtained by :

(a) Thinning out the unbranched one-year-old fruiting shoots.

(b) Cutting back lightly or moderately to laterals the fruiting shoots that are branched.

(c) Thinning out the remaining laterals on these branched shoots.

(d) Heading back the fruiting shoots which are thus left, where experience has shown this to be a desirable practice, either from the standpoint of:

1. Thinning the crop; or

2. Securing new wood growth for the crop of the following year. 
Where possible, it is well to cut to the brownish colored, stocky laterals rather than to shoots that are slender and reddish in color, as the former are better adapted to continue the framework of the tree and generally produce fruit of somewhat higher quality.

In cutting back to a lateral that is likely to bear fruit the following season, it is advisable to leave a short stub just above the lateral-a quarter or one-half inch long-to prevent the lateral from being broken off by the weight of the fruit.

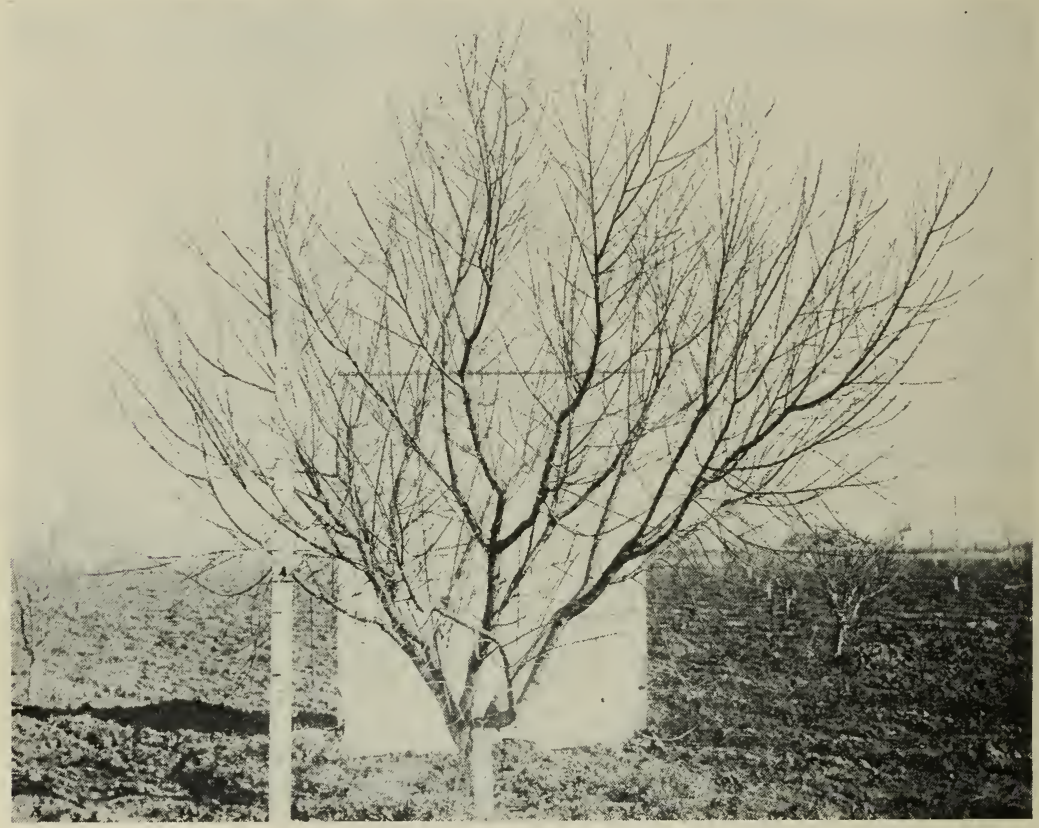

Fig. 14.- Seven-year-old Elberta peach tree before pruning. Note vigorous new wood growth which, however, is not excessive. Compare with fig. 15 after pruning by thinning. This tree has been well pruned during preceding seasons.

Figures 14 and 15 show a young bearing peach tree before and after pruning. This tree has responded well to a thinning treatmentso-called "long pruning."

Pears.-The fruit-bearing habit of the pear is almost identical with that of the apple, and hence suggestions regarding the pruning of the apple apply with equal force to the pear. The pear of course has varietal characteristics just as the apple has. Some varieties tend to come into bearing earlier than others. Likewise, some varieties such as the Bartlett, Winter Nelis, and Angouleme, tend to produce a considerable portion of their crop, especially during the early bearing 
years, at or near the end of one-year wood. The tendency towards alternate bearing is not so pronounced in the pear as in the apple, the fruit spurs are generally a little shorter, and the tree is more upright in habit of growth.

Figure 16 shows an ideal shaped Glout Morceau pear tree. Figure 17 illustrates the pruning of a nine-year-old Bartlett. Under favorable soil and moisture conditions, neglected pear trees sometimes make an

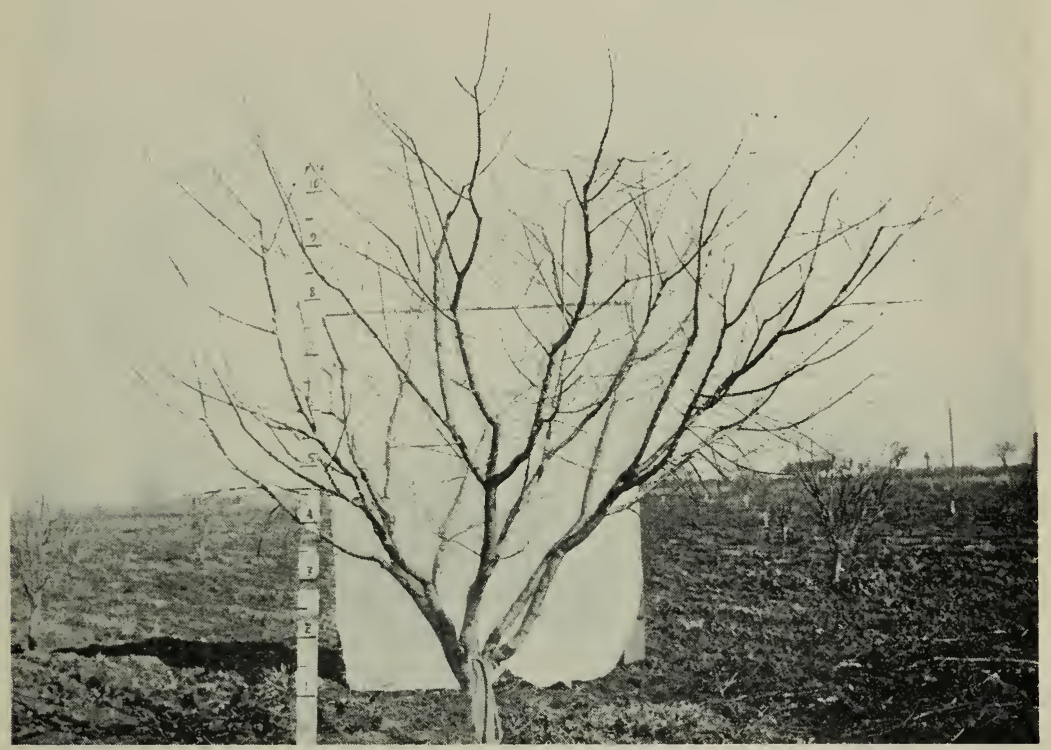

Fig. 15.-A well pruned seven-year-old Elberta peach tree pruned by "thinning out." Compare with fig. 14 before pruning. Note large amount of growth removed. This tree has been pruned for four consecutive years by thinning-no cutting to stubs.

exceptional development (fig. 18). Little or no pruning is not to be generally recommended, but may occasionally be used to advantage on very rich and moist soils, increasing yields and rendering the trees less subject to the ravages of pear blight (Bacillus amylovorous).

Plums and Prunes.-There are two general classes of plums commercially cultivated in California-the Japanese and the European. The former includes only shipping varieties, while the latter includes both shipping plums and prunes. Since the fruiting habit and the pruning of these two species are somewhat different it will be well to divide the discussion into two parts. 
Japanese Plums.-Japanese plums are, in a large part, borne laterally upon short, thick spurs. The spurs are found mostly on wood of from two to six or eight years of age. The life of a spur varies from five to eight years. A minor portion of the crop is borne laterally

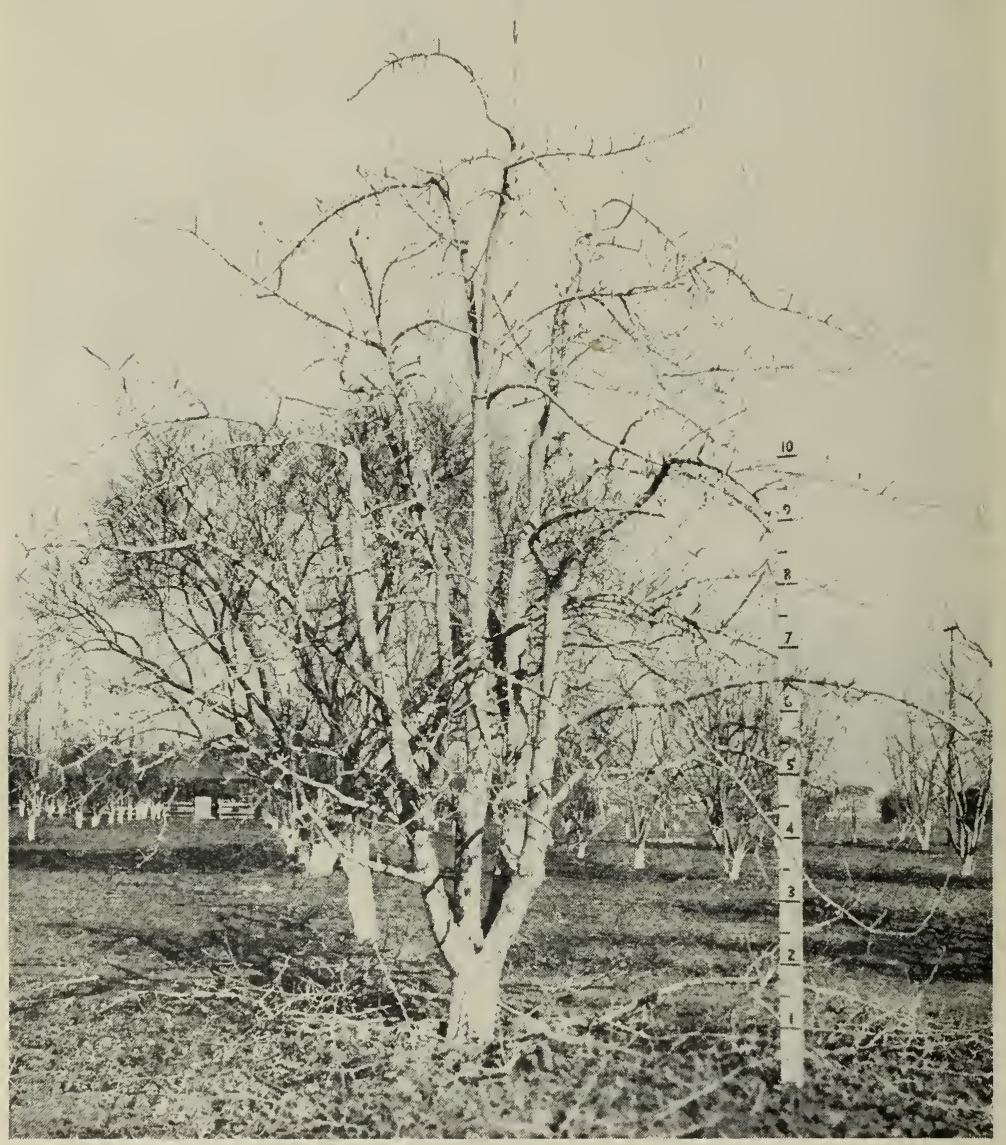

Fig. 16.-A well pruned ten-year-old Glout Morçeau pear tree. Note size of the few scaffold branches. An ideal framework capable of supporting immense crops without breakage. Compare fig. 9 .

on one-year wood, the fruit being produced in general at the basal part of the shoot.

The fruit-bearing habit of the Japanese plum is quite similar to that of the apricot, the principal difference being that the spurs on 
the former are somewhat longer lived. As a natural consequence the pruning of these two fruits is much alike. The fact that the spurs of the Japanese plum are longer lived than those of the apricot would lead one to the conclusion that these plums should be pruned somewhat less severely than the apricot, there being less necessity of replacing the fruiting wood with new shoots. The Japanese plum, however, is most prolific and as only large fruits are commercially valuable, the trees as a consequence must be pruned rather heavily, in order to

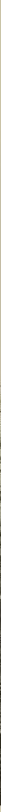

Fig. 17.-A nine-year-old Bartlett pear tree before and after pruning. This tree has been consistently pruned rather lightly, however. Compare fig. 18 of an adjoining tree which has not been pruned for five years. The photographs were taken at same distance from each tree.

reduce the fruit crop and at the same time induce sufficient new wood growth. As a final result, therefore, the severity of the pruning of these two fruits should be very similar. The plum should be pruned in such a way that some ten to twenty-four inches of new wood growth annually is secured on young bearing trees and ten to twelve inches on older ones.

There is considerable difference in the habit of growth of the different varieties. Some varieties such as the Burbank, are rather 
low-spreading growers and attention must be paid even after the trees come into bearing to divert the growth into the more upright branches. On the other hand, the Wickson, Kelsey, and Santa Rosa are examples of varieties that make a very narrow, upright growth and require careful pruning to secure the proper spread.

Figures 19 and 20 show a young bearing Climax plum tree before and after pruning.

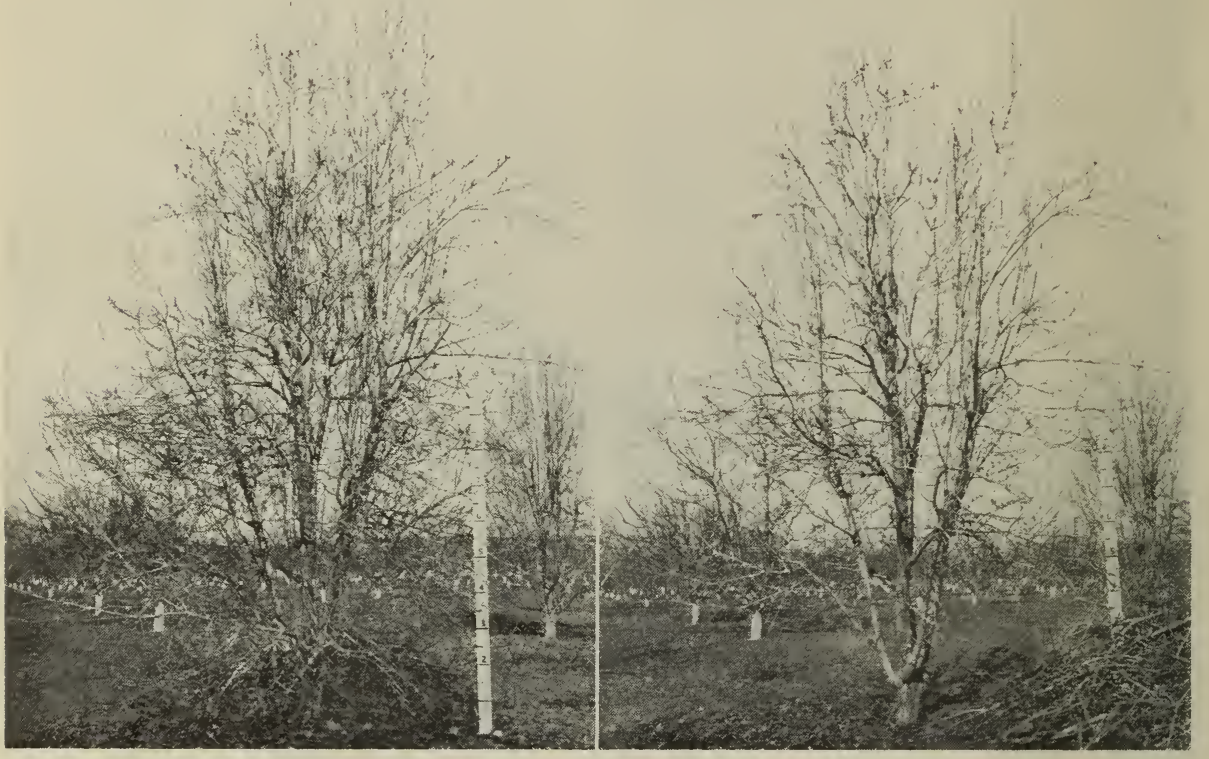

Fig. 18.-A nine-year-old Bartlett pear tree before and after pruning. Deliberately left unpruned for the five years preceding. Note splendid development of fruiting wood and framework branches. Compare fig. 17 of an adjoining tree which has been pruned lightly. In addition to increasing enormously in size this tree has produced from six to eight times as much fruit as the lightly pruned tree. This illustration is introduced not in the way of recommendation but merely to emphasize the greater development secured by little or no pruning so long as the tree makes sufficient new wood growth.

European Plums.-The fruit-spurs of the European plums are quite different from those of the Japanese. They are longer, more slender, and frequently branched. Old spurs, or, as they are sometimes called "fruiting brush," may reach a length of two or three feet, while the spurs of Japanese plums are rarely longer than two or three inches.

The pruning of European shipping plums is very similar to that of Japanese plums, but it is for two reasons a less severe type of 


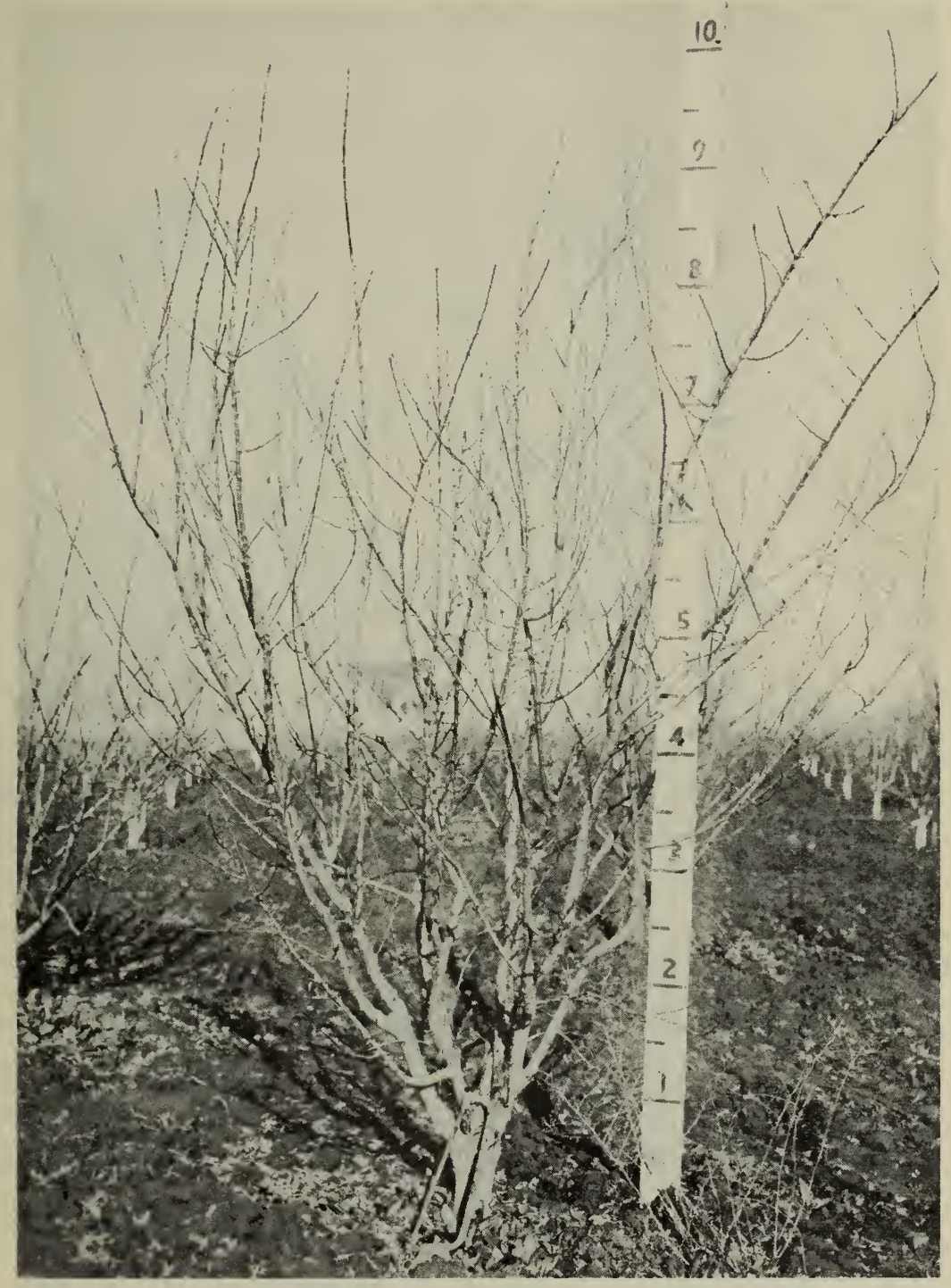

Fig. 19.-A young bearing Climax (Japanese) plum tree before pruning. Note vigorous new wood growth produced by thinning method of pruning. This tree has produced several good erops. Compare with fig. 20. 


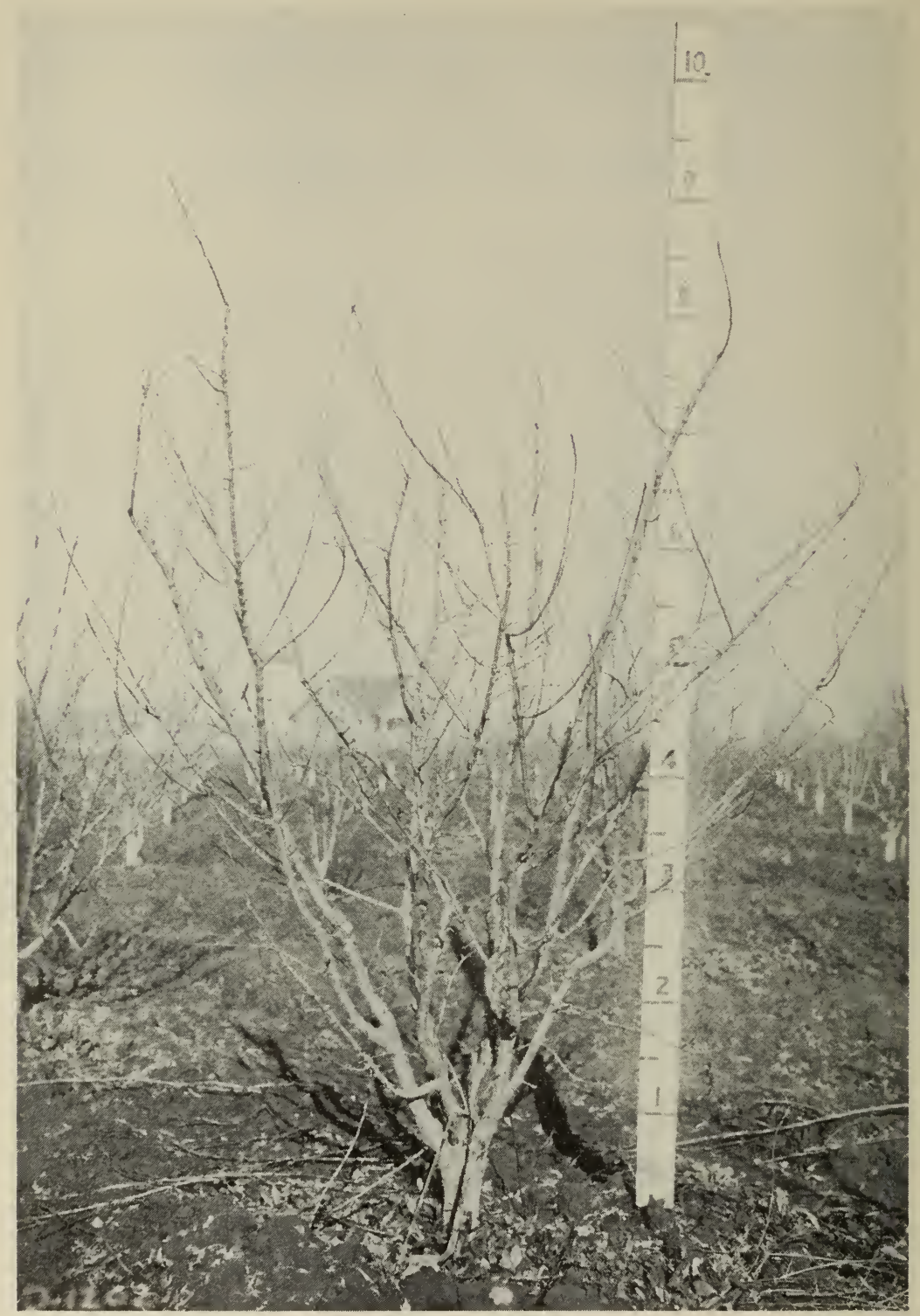

Fig. 20.- Young bearing Climax (Japanese) plum tree after pruning. Compare fig. 19 before pruning. This tree might perhaps have been somewhat better handled by removing two or three of the heavier branches in addition to the thinning of the smaller shoots. A mistake was made in the earlier years in not reducing the number of seaffold limbs. 
pruning. European plums do not tend to over-produce as do the Japanese, hence, a light pruning is sometimes necessary to favor fruitbud formation in the former, rather than a severe pruning to reduce the quantity of fruit-buds as with the latter species. Furthermore, a relatively larger proportion of the fruit of the European plum is borne on spurs. Keeping these facts in mind, the grower may handle the European shipping plums by much the same methods as are described for the Japanese plum and apricot.

The fruiting habit of prunes is identical with that of European shipping plums. The only difference between the two kinds is that in the case of the prunes the mature fruit contains sufficient sugar to dry without fermenting at the pit, while the latter does not. Since, with the exception of the Sugar variety, it is not customary to thin the fruit nor to pick it from the tree, no great attempt has been made on the part of the prune growers to keep their trees within bounds. However, the relation of the operations of pruning and spraying to the height of the tree should not be overlooked.

The pruning commonly given prune trees in this state consists in a rather severe thinning and heading back of both the fruiting brush and the larger limbs. This treatment is often given only at irregular and infrequent intervals. Vigorous new shoots arise near the cuts, necessitating a severe pruning the following season. It often follows that two or three years may elapse before the trees that have been thus heavily pruned again settle down to good production. It seems that one of the most important facts to be emphasized in regard to the handling of prune trees is that the pruning should be done regularly and in most cases should be merely a light thinning out of the shoots, old spurs, and smaller branches (fig. 21). The hanging branches are often cut back to upward and outward pointing limbs in order to keep the tree well shaped. From an economical point of view it is fortunate that few cuts less than a quarter of an inch in diameter are necessary in order to keep sufficient new wood growth coming. An average yearly extension of the leading branches of from nine to eighteen inches is adequate for young bearing prune trees. Older trees should be expected to make at least six inches of growth each summer.

It is a matter of common observation in the older prune orchards that have been given little pruning that the bearing area is located as a thin shell on the periphery of the tree. A branch eight feet long, for example, often has all its fruit-spurs on two or three feet at the terminal end of the branch while the rest of the limb is bare and unproductive. This concentration of the bearing area at the ends of the branches is generally due to an insufficient amount of thinning, 
resulting in a shading out of the interior and lower fruiting wood. Where the fruit-spurs have not been killed they are often long, slender, and unproductive in contrast with the shorter, stockier, fruit-producing spurs to be found on the outside of the tree. Such shaded, willowy spurs produce small fruit and are short-lived. It is obvious that the corrective treatment for such a condition lies in an adequate thinning out of the smaller branches, where the tree has been properly trained,

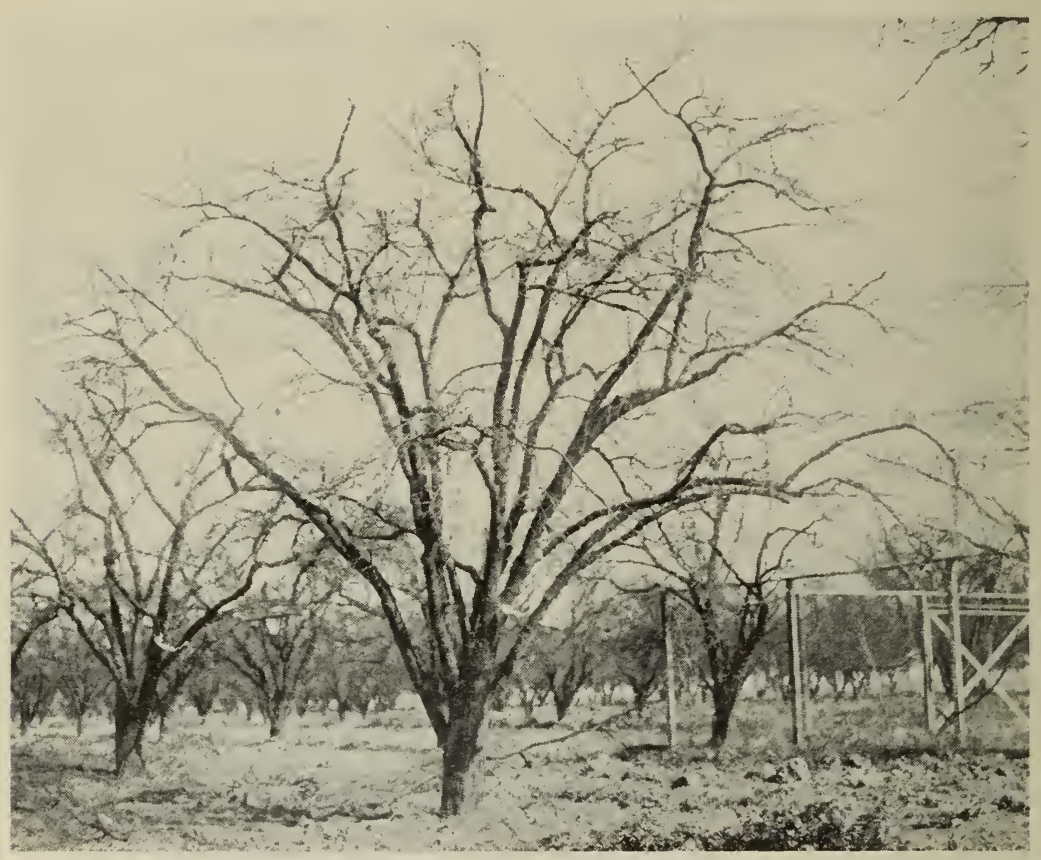

Fig. 21.-Thirty-year-old French prune tree pruned by the removal of a few of the larger branches and a thorough thinning of the "fruiting brush."

and even the removal of a few larger branches, in case the framework is crowded. A word of caution is necessary at this point. Since the prune tree is very susceptible to sunburn, the best of judgment must be exercised in the thinning out of bearing trees as recommended above.

The Sugar prune is a variety which behaves somewhat differently from the other sorts commonly grown in California. It has a pronounced tendency to make the most of its new growth on the tips of the previous season's shoots, in the same manner as does the sweet cherry. It has proved to be an alternate bearer in a number of different localities, and since the wood is brittle, the branches frequently break during the year of heavy production. In the alternate 
years, then, when they have a heavy set of plump fruit-buds, the trees should be pruned heavily, new shoots cut back especially to prevent the formation of long, pole-like branches, and the fruiting wood thinned out. Thinning of the fruit itself may possibly tend to correct this alternating habit. In the off-year, when the set of fruit-buds is rather light, comparatively little pruning, especially in the way of limiting fruit-buds, should be done.

Quinces.-The fruit of the quince is borne terminally on comparatively long current season's shoots, arising from lateral and terminal buds on one-year wood. Since fruit-buds are produced only on one-year wood, attention must be given to the stimulation of such amounts of vegetative growth that the fruiting wood will be renewed annually. Experience has shown, however, that heavy production can generally be secured without a severe pruning. In fact, quinces sometimes continue to bear good crops of large-sized fruit when very little pruning is practiced. It seems best, nevertheless, to give a pruning which will stimulate from 10 to 24 inches of new growth each year on young, and from 9 to 18 inches on older, quince trees. The pruning should consist mainly of a thinning out and heading back to laterals. Occasionally, however, it may be necessary to prune more severely in order to induce sufficient new growth.

\section{ACKNOWLEDGMENTS}

The writer wishes to express his appreciation to the following:

Drs. E. J. Kraus, W. L. Howard, and W. H. Chandler for many helpful suggestions and criticisms in the preparation of the manuscript.

Professor G. L. Philp and Mr. C. L. Austin for help in the field experiments.

Miss Edna Russ for her help in the preparation of the illustrations. 
